\title{
ESTUDIO COMPARATIVO DEL DESARROLLO DE LA VIVIENDA DE INTERÉS SOCIAL EN FLORIDABLANCA, ENFOCADO EN LAS INTERVENCIONES ESTATALES DEL AÑO I 972 Y 2004
}

Susan Dahiana Pinzón Sierra*

Imagen A: Detalle Célula Urbanización Zapamanga, Fuente: Instituto de Crédito Territorial ICT

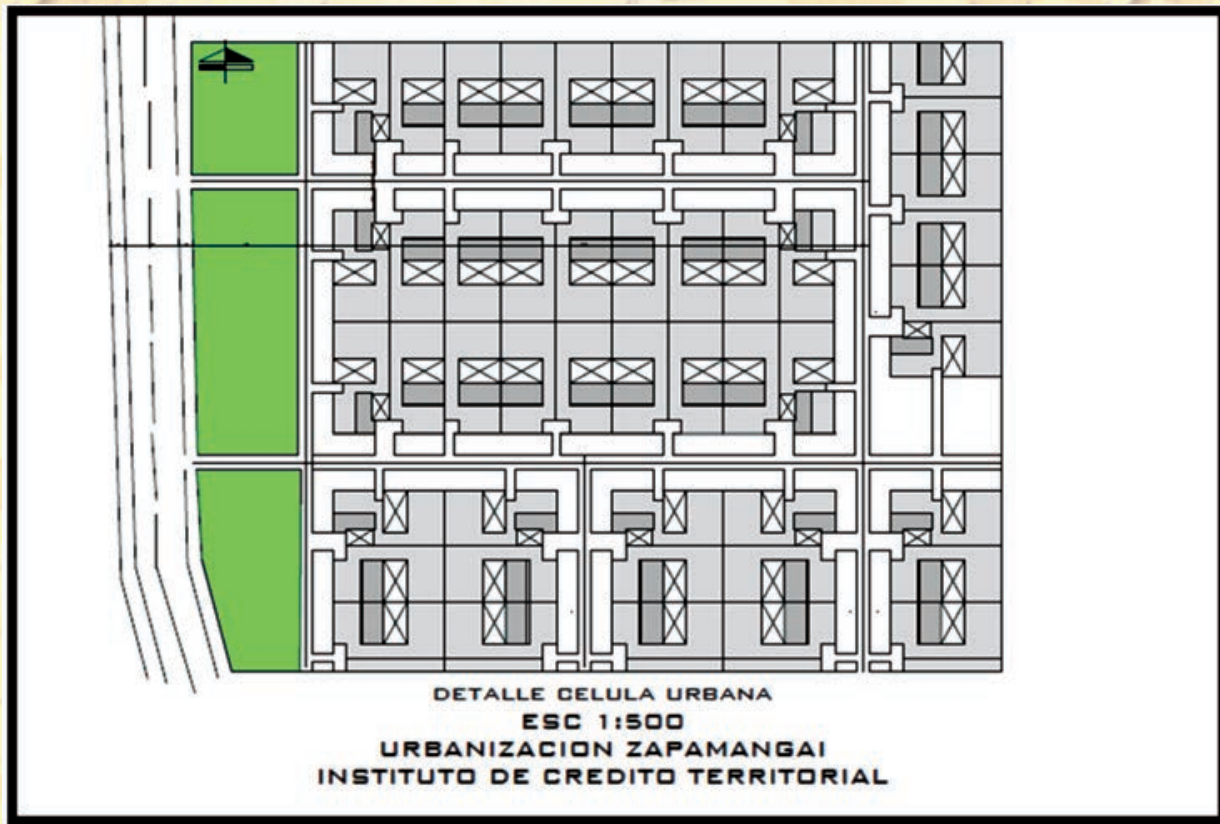

\section{RESUMEN}

La investigación permitió establecer los patrones y proyectos de Vivienda de Interés Social desarrollados en el Municipio de Floridablanca, en el año de 1972 por el Instituto de Crédito Territorial ICT, y la normativa actual estipulada mediante el Decreto 2060 del 24/06 de 2004, por medio del cual se establecieron las normas mínimas en materia de vivienda de interés social, con el objeto de considerar las características inmersas en estas propuestas, determinar sus problemas y proponer un debate crítico que tenga en cuenta las necesidades de sus ocupantes. La situación actual en el país en términos de vivienda de interés social ha motivado el desarrollo de esta investigación, pues se observa que los proyectos y las propuestas gubernamentales contemporáneas, no cumplen los índices de habitabilidad para una calidad de vida digna; por tal motivo, luego de examinar la problemática a fondo se plantea un estudio comparativo, que procura analizar factores externos al ejercicio de la arquitectura, pero que tienen gran incidencia en el resultado final de la vivienda. Para la investigación se recopiló información, con los diferentes actores que participan en el desarrollo de la vivienda de interés social a nivel nacional, departamental y municipal, al igual que aspectos sociológicos, políticos y económicos de amplia incidencia en la solución final de vivienda. Como se trata de un análisis comparativo, fue indispensable plantear variables de orden técnico, social, económico y político, que permitieran encontrar elementos comunes y divergentes con el fin de calificar y cualificar los proyectos, razón por la cual fue necesario realizar visitas al área seleccionada, entrevistas a los residentes y un registro fotográfico de la unidad de vivienda y de su contexto urbano inmediato. En síntesis, se analizaron las intervenciones del arquitecto en estos proyectos y los factores externos que afectaron el desarrollo profesional del mismo.

\section{PALABRAS CLAVE}

Vivienda, Proyecto de Interés Social, Políticas de Estado, Floridablanca. 


\section{A COMPARATIVE STUDY OF SOCIAL HOUSING DEVELOPMENTS IN FLORIDABLANCA, FOCUSED ON STATE LEVEL INTERVENTIONS DURING I 972 AND 2004}

Susan Dahiana Pinzón Sierra*

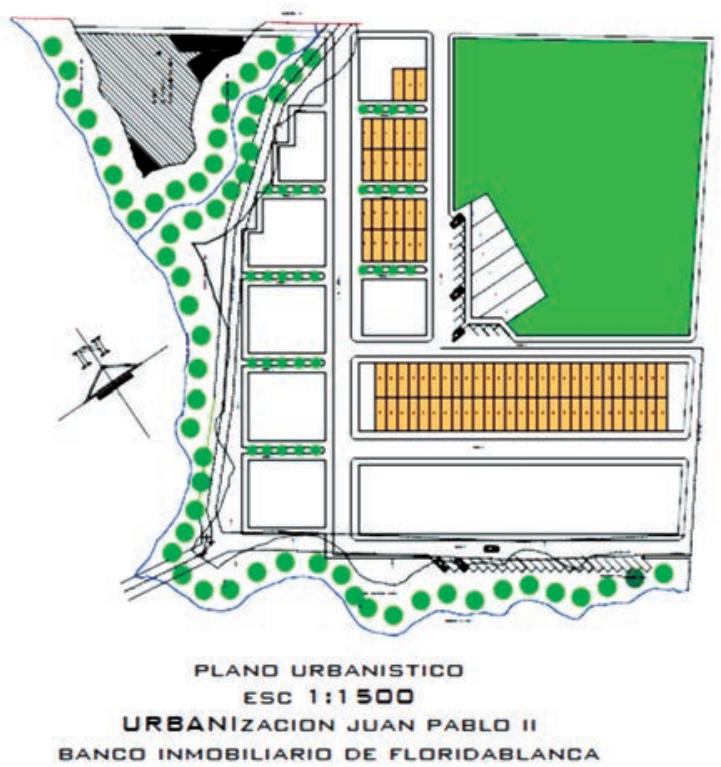

BANCO INMOBILIARIO DE FLORIDABLANCA
Este artículo es producto de la investigación realizada para optar por el título de arquitecta en la Facultad de Arquitectura de la Universidad Santo Tomás, seccional Bucaramanga, la cual fue calificada como meritoria.

El proyecto fue dirigido por el arquitecto Hernando Ladino Barriga.
Imagen B. Plano Turístico, Urbanización Juan Pablo II. Fuente: Banco Inmobiliario de Floridablanca BIF.

\begin{abstract}
This research established patterns and projects of Affordable Housing developed $\mathrm{n}$ the Municipality of Floridablanca, in 1972, by the "Instituto de Credito Territorial (ICT)", and current regulations stipulated by the Law 2060 of June 24, 2004, through which were set out the minimum standards of social housing in order to consider the features embedded in these proposals, identify problems and propose a critical debate that takes into account the needs of its inhabitants. The current situation in the Country, in terms of social housing, has encouraged the development of this research, since it is noted that projects and contemporary government proposals do not fulfill the occupancy rates for a dignified life. Thus, after thoroughly examining the issue, raises a comparative study that seeks to examine external factors to the practice of architecture, but that have great impact on the outcome of the housing. In order to conduct the investigation, information was collected between the different actors involved in the development of affordable housing, at national, departmental and municipal levels, as well as sociological, political and economic effects of widespread occurrence in the final solution of housing. As this is a comparative analysis, it was essential to raise technical, social, economic and political variables that allowed finding commonalities and divergences in order to classify qualify and qualify the project. Thus, it was necessary to make visits to the selected area and to conduct interviews with residents, taking a photographic record of the housing unit and the immediate urban background. In other words, the interventions of the architect were examined on these projects as well as the external factors that stroked his professional performance.
\end{abstract}

\title{
KEY WORDS
}

Housing, Social Interest Project, State Policies, Floridablanca. 


\section{INTRODUCCIÓN}

La vivienda es un bien necesario del que carece un amplio sector de la población vulnerable en Colombia. Para mitigar esta insuficiencia el Estado, responsable directo de fomentar programas de vivienda y gestionar recursos para que estos desarrollos sean posibles, se ha encargado de implementar políticas que van en detrimento de los mismos. De allí el interés por delimitar dos períodos históricos relevantes en materia de vivienda 1972 y 2004, dos gobiernos con lineamientos diferentes que proponen y ejecutan proyectos que marcan indicadores de calidad arquitectónica y urbanística. Estos indicadores ponen en evidencia qué tan efectivos y óptimos fueron estos programas y el impacto que tuvieron entre sus beneficiarios.

El déficit de vivienda en Colombia, la calidad de la misma y su espacio urbano inmediato, no han dejado de ser un tema ampliamente debatido, por tratarse de un problema que afecta a un alto porcentaje de los habitantes de la nación. Es por esto que al observar la ciudad, la vivienda aparece como un elemento importante de la estructura urbana, ya que es la unidad mínima de desarrollo social, donde la familia como núcleo de la sociedad, realiza sus actividades cotidianas. Las personas en situación de vulnerabilidad, los desplazados por la violencia, los destechados por fenómenos naturales y los emigrantes de las zonas rurales, entre otros grupos y comunidades en riesgo, aspiran a una mejor calidad de vida al instalarse en los centros urbanos; sin embargo, acceder a este bien, se torna complejo pues las ofertas del mercado de la construcción, hacen que ésta sea poco accesible para las personas, razón por la cual hace su aparición por iniciativa del Estado colombiano la Vivienda de Interés Social, como una solución a esta problemática, se delinean características muy precisas que contribuyen a la formación de la trama urbana de la ciudades.

El ejercicio de la Arquitectura cobra importancia en la proyección y ejecución de este tipo de soluciones habitacionales; cabe señalar que el resultado final de estos proyectos está ligado a una serie de factores externos y ajenos al arquitecto, por ello debe ser imperativo estar dispuesto no sólo a atender una serie de lineamientos técnicos, sino también a otros de carácter humanista; es así como el desarrollo de las competencias del profesional de la arquitectura, está enfocado a generar propuestas que no predispongan mayores afectaciones para el futuro, ya sea desde el campo de la construcción, proyección y promulgación de normativas, encaminadas a equilibrar los impactos sobre el medio. De allí la urgencia de plantear desde la academia, el estudio del proyecto arquitectónico de la VIS no sólo como salida a un problema de funcionalidad espacial, sino también como respuesta a las necesidades básicas de las personas, que requiere de un estudio interdisciplinario que proporcione soluciones integrales.

\section{DELIMITACIÓN TEMPORAL DEL PROYECTO}

La investigación se trazó por objetivo el análisis de la Vivienda de Interés Social en el municipio de Floridablanca y los factores asociados a la calidad de la misma, por esta razón se tomaron dos momentos coyunturales en la historia de Colombia relacionados con estos desarrollos: 1972 año en el cual el Presidente Misael Pastrana Borrero, propuso un plan que incentivaba la construcción de la vivienda y la generación masiva de empleos mediante la financiación privada con base en un nuevo sistema de valor constante; estas directrices dispuestas desde la gerencia nacional, estaban íntimamente ligadas a la solución de la problemática del déficit de vivienda. Para llevar a cabo estos planes, el Estado se apoyó en el Instituto de Crédito Territorial, como ente encargado de planificar y ejecutar estos proyectos. 
En el año 2004 en el Gobierno de Álvaro Uribe Vélez, la política estaba orientada a la promoción y fomento de esquemas de asociación mixta para la investigación y desarrollo, en tecnologías de aumento de la productividad y mejoramiento de la calidad de la vivienda de interés social, que permitieran incrementar las condiciones de acceso a la misma y un razonable aprovechamiento de los recursos, reconociendo las singularidades urbanoregionales del país. Para llevar a buen término estas propuestas desde el Ministerio de Ambiente, Vivienda y Desarrollo Territorial, se encaminaron las políticas a la tercerización de los procesos de ejecución en manos de entidades evaluadoras, operadoras y supervisoras de proyectos.

Estos dos momentos marcaron una diferencia en las políticas de vivienda y, a su vez, en la proyección y ejecución de los proyectos, que se ve reflejada en la ciudad, y como ésta es la expresión social sobre el territorio y uno de los principales términos de referencia para el estudio de la Arquitectura, es entonces imperativa la vinculación de la academia, docentes y estudiantes, para conocer a fondo el tema de la VIS, no sólo desde el punto de vista urbanístico y arquitectónico, sino también como solución a la problemática de las personas que carecen de una vivienda digna, con todas la implicaciones de no tenerla, para así lograr un debate crítico de las condiciones actuales, y plantear respuestas acordes a los retos que el presente ofrece.

\section{OBJETIVOS DE LA INVESTIGACIÓN}

\section{General}

Desarrollar un estudio comparativo que permita analizar y visualizar las transformaciones urbanísticas y arquitectónicas de la Vivienda de Interés Social en Floridablanca, que tenga como referente las políticas estatales, ejecutadas en 1972 por el Instituto de Crédito Territorial, y en el año 2004 por el Ministerio de Ambiente, Vivienda y Desarrollo Territorial de Colombia.

\section{Específicos}

- Estudiar los planes y propuestas implementados por el Instituto de Crédito Territorial ICT en materia de vivienda de interés social en la década de los setenta en el Municipio de Floridablanca.

- Identificar cada uno de los parámetros expuestos por el Ministerio de Ambiente, Vivienda y Desarrollo Territorial en 2004, relacionados con esta temática.

- Comparar los elementos comunes y divergentes de estas dos propuestas de vivienda de interés social con el propósito de hacer un análisis de la situación de la vivienda en Floridablanca con las variables técnicas, económicas, políticas y sociales que han dado como resultado la vivienda actual.

\section{MOMENTO 1972: DE LAS POLÍTICAS ESTATALES}

El programa de gobierno designado "Las Cuatro Estrategias", recogía las directrices diseñadas por el economista canadiense Lauchlin Currie, para dinamizar y diversificar la economía colombiana: concentración de la inversión en el desarrollo urbano, fomento a las exportaciones, aumento de la productividad agrícola e impuestos progresivos para la inversión en servicios sociales. 
La primera estrategia estaba enfocada al desarrollo urbano, al concentrar recursos en la industria edificadora, tanto de vivienda como de servicios complementarios, ella conduciría no sólo a la producción de bienes esenciales que eran requeridos con urgencia por vastos núcleos sociales, sino que esperaba la generación de empleos adicionales que de inmediato contribuirían al ensanche del mercado interno, al elevar el nivel de consumo y facilitar entonces, con su demanda, incrementos en la producción industrial y agrícola del país sin deteriorar los ingresos reales de los productores'.

En la segunda estrategia, el incremento de las exportaciones, es en el caso colombiano, la conditio sine qua non para poder garantizar no sólo el suministro de las importaciones requeridas sino atender con holgura el servicio de la creciente deuda externa; así mismo, la ampliación de la participación en los mercados internacionales para productos de exportación contribuyó de manera especial a facilitar el incremento de la producción agrícola.

La tercera estrategia estaba relacionada con el aumento de la productividad agrícola y con una mejor distribución de la propiedad rural, por consiguiente, se podía esperar una racional redistribución de la tenencia de la tierra que además tenía en cuenta climas, regiones y productos.

La cuarta estrategia se refería a la redistribución del ingreso y se fundamentaba esencialmente en un sistema progresivo de impuestos donde se tributara de acuerdo con la capacidad real para hacerlo y donde se eliminaban las medidas que pudieran distorsionar el sistema tributario hasta hacerlo regresivo; en segundo lugar, se basó en una acertada política del gasto público que orientaba y concentraba los recursos estatales hacia los servicios públicos, en particular hacia la educación, la salud y la recreación; y, finalmente con el éxito de la primera estrategia del plan (generación de empleos adicionales bien remunerados), se facilitó que los ingresos reales de los grupos más pobres, fueran más altos.

Es importante señalar que para lograr el desarrollo de esta iniciativa, se creó un esquema denominado ciudades dentro de la ciudad² que buscaba la expansión urbana debido al acelerado proceso de urbanización; el alza en los precios de la tierra urbana ocasionado por las demandas de nuevas tierras para la edificación y la no coordinación de la actividad de los organismos estatales y de la empresa privada, contribuyeron a acentuar la dispersión urbana, que ocasionaba el aumento de los costos sociales (transporte, infraestructura y servicios, entre otros) y el uso irracional del suelo urbano y los recursos. Se trazaron para ello los siguientes objetivos:

- Racionalización de los usos del suelo.

- Racionalización de las inversiones tanto del sector público como del privado.

- Racionalización del diseño urbano y de vivienda.

Para cumplir los lineamientos de la primera estrategia era preciso fortalecer las políticas de vivienda popular y concentrar en los institutos gubernamentales los recursos presupuestales y subsidiados, además fortalecer el Instituto de Crédito Territorial con políticas de tierras y nuevos programas donde se articularan las Corporaciones de Ahorro y Vivienda. Las

I Departamento Nacional de Planeación. Plan de Desarrollo Las Cuatro Estrategias, Gobierno Misael Pastrana Borrero. Bogotá, 1972

2 MOLINA, Humberto. (Editor). Colombia: Vivienda y Subdesarrollo Urbano. C.P.U. Universidad de Los Andes, Bogotá, I979 
políticas de tierras se enfocaban hacia las ciudades intermedias al financiar los servicios públicos como alcantarillado, acueducto y energía eléctrica.

EI ICT, como entidad encargada de llevar a cabo los proyectos de vivienda, desplegó una serie de estrategias entre las que se cuenta el desarrollo progresivo de los barrios piratas y asentamientos subnormales, mediante acciones integrales que permitieran su incorporación al desarrollo urbano. Esta estrategia se realizaría mediante programas de asistencia técnica a las ciudades intermedias y menores, para formular proyectos de renovación urbana en sectores marginales. De igual forma se planteó la legalización (legalización y distribución de tierras, apertura de créditos hipotecarios para dotación de servicios a través de los municipios, dotaciones comunales para servicios urbanos de escuelas, centros de salud, mercado, acción comunal y otros edificios de uso colectivo).

Otra opción fue la construcción de vivienda de desarrollo progresivo, para atender el déficit cuantitativo de vivienda urbana de interés social, se ofrecieron para ello los programas:

- Soluciones básicas (de $41 \mathrm{~m}^{2}$ a $60 \mathrm{~m}^{2}$ de construcción)

- Soluciones intermedias (de $61 \mathrm{~m}^{2}$ a $90 \mathrm{~m}^{2}$ de construcción)

- Soluciones máximas (de más de $90 \mathrm{~m}^{2}$ de construcción)

- Mejoramiento de la comunidad, con programas de desarrollo social económico y de organización de la misma.

En este período las políticas gubernamentales estaban encaminadas a la captación de ahorro, ya que se consideraba que gran parte de la población tenía una capacidad de ahorro que no se había sabido aprovechar. Para incentivar el crédito se crearon las Cajas de Ahorro y Vivienda, que pretendían estimular la competencia y evitar los monopolios, promover economías de escala y bajos costos de operación, por medio de volúmenes adecuados de operación a nivel de cada corporación, estimular el desarrollo regional por medio del incremento del ahorro y de la construcción en las distintas ciudades del país, generar sistemas de ahorro establecidos para las Cajas de Ahorro y Vivienda y cuentas de ahorro de valor constante que ofrecían un interés del $50 \%$ anual sobre los saldos mínimos trimestrales expresados en UPAC, al tiempo que certificados de ahorro de valor constante, con una tasa de interés anual, consignados en certificados que no podían ser expedidos con menos de seis meses, es decir, que el ahorrador no podía retirar sus ahorros si no quería perder sus intereses.

Todas estas regulaciones y mecanismos de ahorro eran vigilados por la Junta de Ahorro y Vivienda, encargada de mantener el sistema actualizado, calcular mensualmente e informar a las CAV, los valores del UPAC en moneda legal, de acuerdo con la variación resultante del promedio del índice nacional de precios al consumidor, para empleados y para obreros elaborado por el DANE, para el período trimestral inmediatamente anterior.

La política urbana de esta época, puede considerarse como la política más acabada y coherente en esta materia, pues combinó distintos intereses: el capital industrial (particularmente el constructor), podría resolver en cierta medida la barrera de escasez de financiación para esta actividad, mediante el crédito otorgado por las Corporaciones de Ahorro y Vivienda para la producción y el consumo de este bien. La política circunscrita, además de tratar de resolver un problema social como el desempleo, garantizaría el capital 
de la construcción, ampliaría la masa de plusvalía obtenida al diversificar sus procesos, ya fuera en la construcción o en la producción de materiales.

\section{INSTITUTO DE CRÉDITO TERRITORIAL -ICT-}

Fue un organismo del Estado colombiano dependiente del Ministerio de Desarrollo Económico, destinado a construir, promover y financiar la vivienda popular. Además, colaboró para que las ciudades colombianas lograran un crecimiento más adecuado a las necesidades de la comunidad. Para ello contaba con una serie de recursos y programas que permitían el control y seguimiento de los proyectos desde su etapa inicial (planteamiento) hasta su finalización (entrega de la vivienda) ${ }^{3}$

Los programas que ofrecía el ICT estaban relacionados con la autoconstrucción, es decir, con la organización de las adjudicaciones para que los usuarios construyeran ellos mismos sus viviendas, ahorraban de este modo el costo de la mano de obra; para ello se valdrían de la capacitación que para entonces ofrecía el SENA, en lo referente a la enseñanza de técnicas de construcción. Quienes poseían un lote, recibían del Instituto préstamos para adquisición de los materiales constructivos. Otras modalidades buscaban la interacción con el sector privado, abogaban por la financiación y construcción de viviendas populares por el sistema P-3 o sistema cofinanciado por tres: ICT-Comprador-Constructor.

Se apeló al desarrollo de las construcciones mediante licitación pública, se otorgaba el contrato de construcción a la propuesta que presentara las condiciones más favorables para las familias y motivaba al constructor particular para que aportara su experiencia y capacidad técnica, empresarial y financiera en la búsqueda de soluciones de vivienda más económicas mediante nuevos materiales y nuevas técnicas.

Para lograr que la vivienda popular tuviera características arquitectónicas y urbanísticas apropiadas a las necesidades de los usuarios y que, en el futuro permitiera un desarrollo progresivo óptimo y de integración con la trama urbana del municipio, se planteó una normatividad de carácter programático, planificador y de dirección, realización y de control de todos los procesos para los proyectos ${ }^{4}$. De igual manera el objeto del estudio contempló, el establecimiento de normas realistas que permitieran desarrollar una política correctiva sobre los barrios subnormales existentes, y una política preventiva, mediante soluciones de mejoramiento, de allí el surgimiento del Estudio de Normas Mínimas de Urbanización, Servicios Públicos y Servicios Comunitarios, proferidas por el Departamento Administrativo de Planeación Nacional.

\section{ESTUDIO DE NORMAS MÍNIMAS DE URBANIZACIÓN, SERVICIOS PÚBLICOS Y SERVICIOS COMUNITARIOS}

Para seguir con el fortalecimiento de las entidades gubernamentales encargadas de la planeación y producción de vivienda, implementadas en el plan de gobierno y específicamente en la primera estrategia, el ICT en colaboración con un grupo interdisciplinario de profesionales en economía, urbanismo, acueducto y alcantarillado, electricidad y pavimentos, desde el Departamento Administrativo de Planeación Nacional, expidió una serie de Normas Mínimas que buscaban soluciones de vivienda de subsistencia decorosa con requerimientos modestos y que pudieran realizarse por etapas, para así mitigar la problemática de déficit

Instituto de Crédito Territorial, Seccional Santander. 40 años Construyendo Vivienda para el Pueblo Colombiano. Programas de Vivienda.

4 Revista Escala No. 35 
habitacional de los centros urbanos ${ }^{5}$. Los estándares razonables pretendieron asegurar mejores soluciones a las espontáneas y de baja calidad que se observaban en la práctica.

Los acelerados procesos de urbanización marcaron pautas para el enfoque de los nuevos proyectos habitacionales, tenían como referente el desarrollo programático y sistemático de los barrios, basados en características ambientales y de habitabilidad. En las primeras se contempla el contexto macro del proyecto, en tanto que las segundas, se relacionan con el desarrollo de la unidad de vivienda.

Características ambientales: infraestructura de servicios en que se implanta, el equipamiento comunal que lo complementa y el contexto urbano.

Características de habitabilidad: ocupación en la vivienda, dimensionamiento espacial, que responden a las funciones que en ellos se realizan.

Para lograr resultados reales en materia de soluciones de vivienda, se obligó a atender a ciertos parámetros que hicieran viable que las personas que las necesitaran pudieran acceder sin mayor complicación a ellas, para lo cual se planteó la urgente compatibilidad con la capacidad económica de los usuarios, para así conseguir que ellos obtuvieran títulos propios que generarían un sentido de pertenencia que se vería reflejado en el progreso de la ciudad.

Un ejemplo de ello fue recurrir a un dato teórico de menor magnitud y ajustado a las necesidades de cinco personas, según el cálculo basada en estándares estudiados previamente por el ICT, que daba un valor de 80 metros cuadrados (considerados $40 \mathrm{~m}^{2}$ iniciales de construcción y adicionados $20 \mathrm{~m}^{2}$ como reserva de ampliaciones y $20 \mathrm{~m}^{2}$ de área no construida para aire, luz y actividades exteriores para lo cual se fijó una consideración de área construida por persona ${ }^{6}$. (Ver Cuadro I)

Cuadro I. Área construida por persona según diferentes tipos de composición familiar

\begin{tabular}{|c|c|c|c|c|c|c|c|c|}
\hline Personas & 1 & 2 & 3 & 4 & 5 & 6 & 7 & 8 \\
\hline Área Vivienda en $\mathrm{m}^{2}$ & 10 & 17.5 & 25 & 32.5 & 40 & 47.5 & 55 & 65.5 \\
\hline $\mathrm{m}^{2} /$ persona & 10 & 8,75 & 8,33 & 8.13 & 8,0 & 7,92 & 7,86 & $7,81-$ \\
\hline
\end{tabular}

Fuente: Schmitz-Reig, Op. Cit: y Reig: "Ubicación y calidad de la vivienda”.

Este proyecto tiene como condición el aumento de densidad, que pretenderá una mejor ocupación del suelo y bajar los costos de la urbanización. Las Normas Mínimas, fueron esbozadas desde la configuración del contexto urbano (terreno, infraestructura de servicios públicos, densificación del lote) hasta el diseño de la unidad de vivienda, análisis de su desarrollo espacial, respuesta a unas necesidades básicas, y previsión de futuras mejoras progresivas.

5 Instituto de Crédito Territorial, Departamento Administrativo de Planeación Nacional. Estudio de Normas Mínimas de Urbanización, Servicios Públicos y Servicios Comunitarios.

6 MOLINA, Humberto. Op. Cit. 


\section{SISTEMAS DE FINANCIACIÓN Y ADJUDICACIÓN}

El ICT contaba con diversos programas de financiación que dependían del tipo de programa de vivienda, cuyas necesidades se atendían así:

Realizaba programas de lotes con servicios a precios de venta populares, para que las familias que no disponían de ingresos suficientes para adquirir una casa, pudieran adquirir un terreno financiado por el Estado.

Construía soluciones básicas de vivienda para familias cuyos ingresos eran iguales o menores al salario mínimo legal.

Ayudaba al mejoramiento de las condiciones de vida de las familias que habitaban vivienda en mal estado y sin servicios.

\section{PLANES DE VIVIENDA}

- Cofinanciados: eran programas que promovían y se ejecutaban con la participación de capital privado, aportado por personas naturales y jurídicas en calidad de promotores, financiadores y constructores, entre otros.

- Autoconstrucción: denominado esfuerzo propio y ayuda mutua, estaba dirigido a familias de bajo nivel económico, que debido a sus escasos ingresos no tenían acceso a las cuotas de una casa terminada; permitían la participación de la comunidad a través del aporte de trabajo durante la construcción de la vivienda.

- CIS (crédito individual supervisado): consistía en un préstamo individual donde el I.C.T concedía al beneficiario (de cooperativas, federaciones, comités), la oportunidad de legalizar la tenencia de lotes, construcción de vivienda y mejoramiento de la misma.

- I.P.C (integración de servicios y participación de la comunidad): Se trató de un programa que se realizaba en las zonas subnormales. El dinero de estas obras era asignado directamente por la Presidencia de la República y el INSCREDIAL, encargado de adelantar la construcción de viviendas para aquellas familias que habían quedado sin techo.

- Créditos y adjudicaciones: toda familia que llenó los requisitos exigidos, pudo llegar a ser adjudicatario sin necesidad de intermediarios.

$\bullet$

REQUISITOS PARA COMPRA DE VIVIENDA: Para ello se necesitaba demostrar que no se era propietario de vivienda o lote en ninguna ciudad del país; que el solicitante era colombiano y cabeza de un grupo familiar y que el ingreso de todo el grupo familiar estaba de acuerdo con el tipo de vivienda que solicitaba. Las formas de pago eran de contado y el plan alcancía ${ }^{7}$. La selección de adjudicatarios se realizaba mediante un sorteo celebrado en presencia de un delegado de la Contraloría General de la República.

$7 \quad$ El Plan Alcancía se contempló como la manera más factible para que el adjudicatario pagara la cuota inicial, con abonos mensuales mientras duraba el proceso constructivo. 


\section{ANÁLISIS DEL PROYECTO ZAPAMANGA I ETAPA}

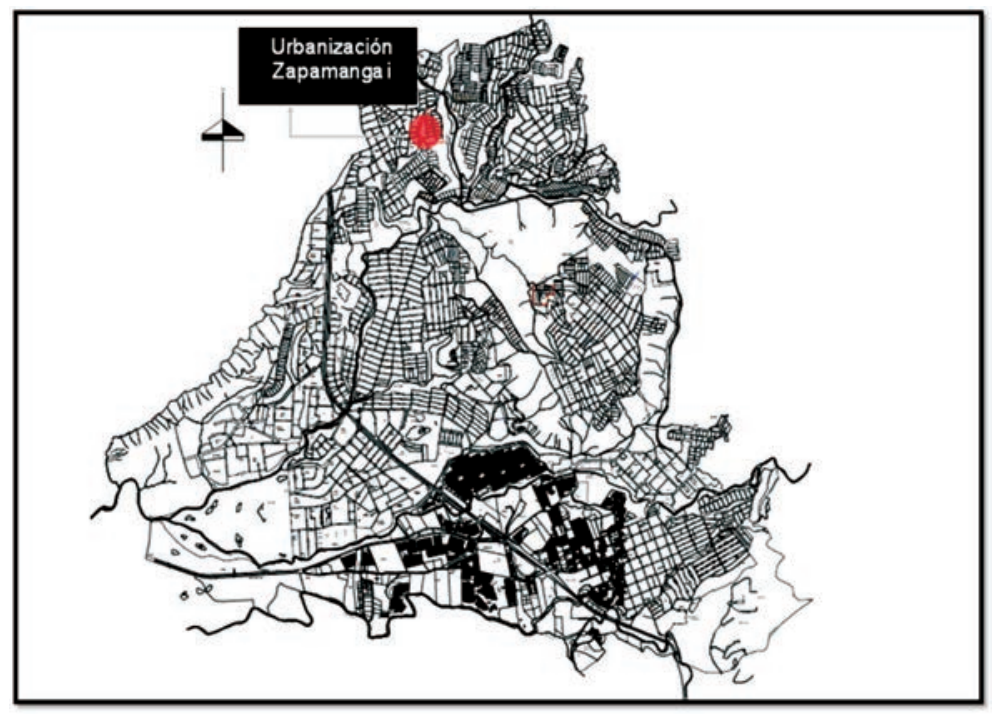

La urbanización Zapamanga (Ver Cuadro 2.), es un obra realizada en el año de 1976, se tomó como referencia las políticas sustentadas en el Plan de Las Cuatro Estrategias, que buscaba el fortalecimiento de la construcción como elemento que dinamizaría la economía y, lo más importante, que contribuyera a dotar de un hogar digno a la población menos favorecida del país.

Mediante escritura pública No. 3229 del 21 de septiembre de 1.97I, el Instituto de Crédito Territorial adquirió el predio denominado Zapamanga, situado en Jurisdicción de Floridablanca, con un área de 512.139.6I metros cuadrados. Aunque la urbanización se desarrolló en siete etapas, en este estudio se tendrá en cuenta la primera etapa.

Cuadro 2. Ficha Técnica de Análisis del Proyecto

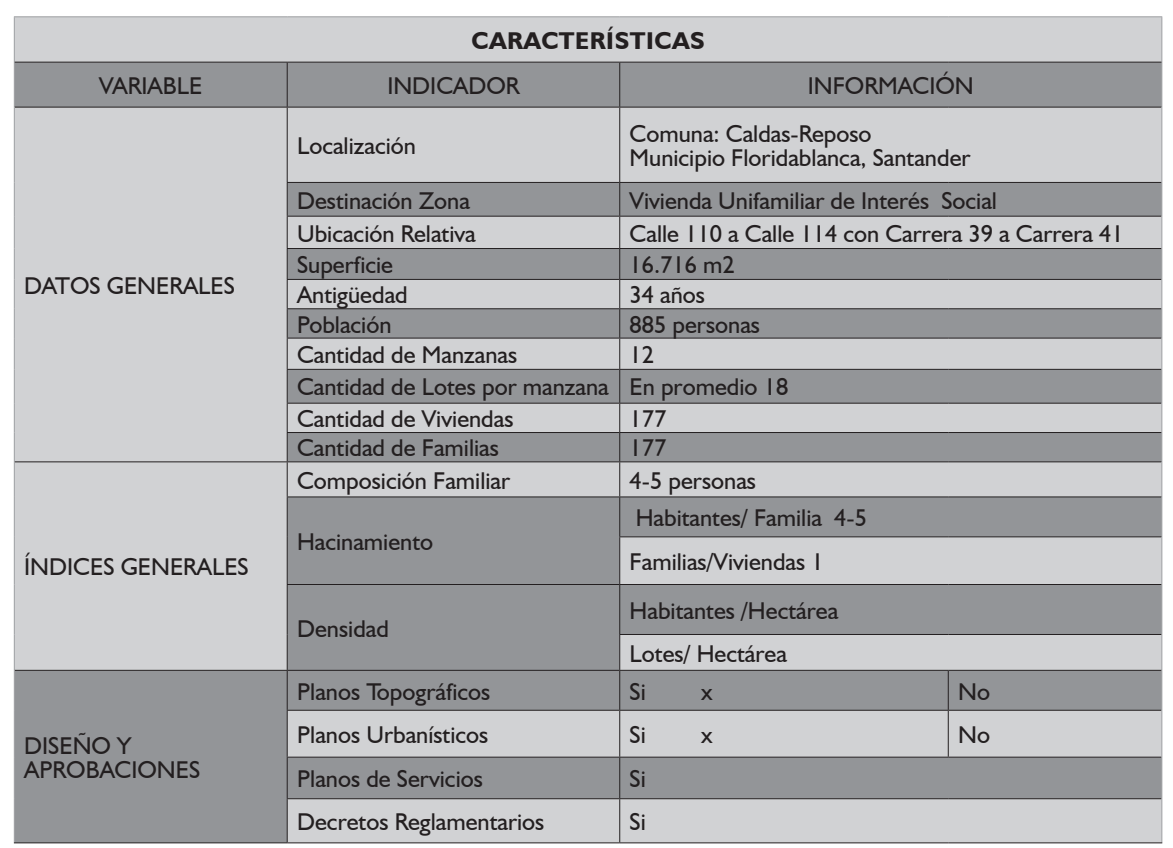

Imagen I. Localización de la Urbanización Zapamanga I en Floridablanca Fuente: Mapa Urbano. Plan de Ordenamiento Territorial Floridablanca 


\begin{tabular}{|c|c|c|}
\hline \multirow{6}{*}{ INFRAESTRUCTURA } & Vías & Si Vehiculares y peatonales \\
\hline & Agua Potable & $\mathrm{Si}$ \\
\hline & Aguas Negras & $\mathrm{Si}$ \\
\hline & Aguas Lluvias & $\mathrm{Si}$ \\
\hline & Energía & $\mathrm{Si}$ \\
\hline & Teléfono & Algunas Viviendas, 2 por manzana \\
\hline \multirow{2}{*}{$\begin{array}{l}\text { ESTADO DE LA } \\
\text { VIVIENDA }\end{array}$} & Como fue entregada & Primera fase del desarrollo progresivo \\
\hline & Mejoramiento & De acuerdo a la disponibilidad presupuestal de la familia \\
\hline \multirow{10}{*}{$\begin{array}{l}\text { EQUIPAMIENTO } \\
\text { COMUNITARIO }\end{array}$} & Comercio & Si, tiendas, panaderías, ferreterías \\
\hline & Educación & Si, Escuela Fe y Alegría \\
\hline & Salud & $\mathrm{Si}$ \\
\hline & Religiosos & Si, Iglesia Jesús de Nazaret \\
\hline & Socio-Cultural-Recreativos & Espacios designados \\
\hline & Deportivos & Espacios designados \\
\hline & Transporte & Si. Rutas de buses Cotrander-Unitransa \\
\hline & Recolección de Basuras & $\mathrm{Si}$ \\
\hline & Nomenclatura. & $\mathrm{Si}$ \\
\hline & Seguridad & Vecinal \\
\hline
\end{tabular}

Fuente: Elaborado por la autora

\section{ASPECTOS SOCIALES}

La Urbanización Zapamanga I Etapa, se proyectó con el fin de dar solución de vivienda a familias de escasos recursos del Municipio de Floridablanca. Debido a sus bajos ingresos y a la poca posibilidad de adquirir un crédito, el ICT propuso un programa de autoconstrucción que motivaba la participación de las familias en la construcción de sus viviendas, con el fin de crear una sinergia entre el Instituto y los beneficiarios, al reunir recursos humanos y económicos, para cumplir con el objetivo de proveerles una vivienda. La dinámica de estos programas funcionaba desde el Instituto, quien era el encargado de otorgar el lote y facilitar los préstamos para que las familias, de acuerdo a sus propios recursos y posibilidades, con colaboración técnica y seguimientos por parte de los profesionales del ICT, construyeran su casa y progresivamente la mejoraran y ampliaran hasta lograr cumplir con los requerimientos del grupo familiar. Este sistema permitió rebajar notablemente los costos de la construcción y para desarrollar el proyecto, los beneficiarios del programa debieron trabajar en grupos de 30 a 50 personas los fines de semana, aunque la ubicación de su respectiva vivienda se dio de acuerdo a su desempeño en el proyecto (Ver Imagen 2).

Imagen 2. Finalización primera parte del Proyecto Zapamanga I Etapa Fuente: Instituto de Crédito Territorial, Seccional Santander. 40 años Construyendo Vivienda para el Pueblo Colombiano.

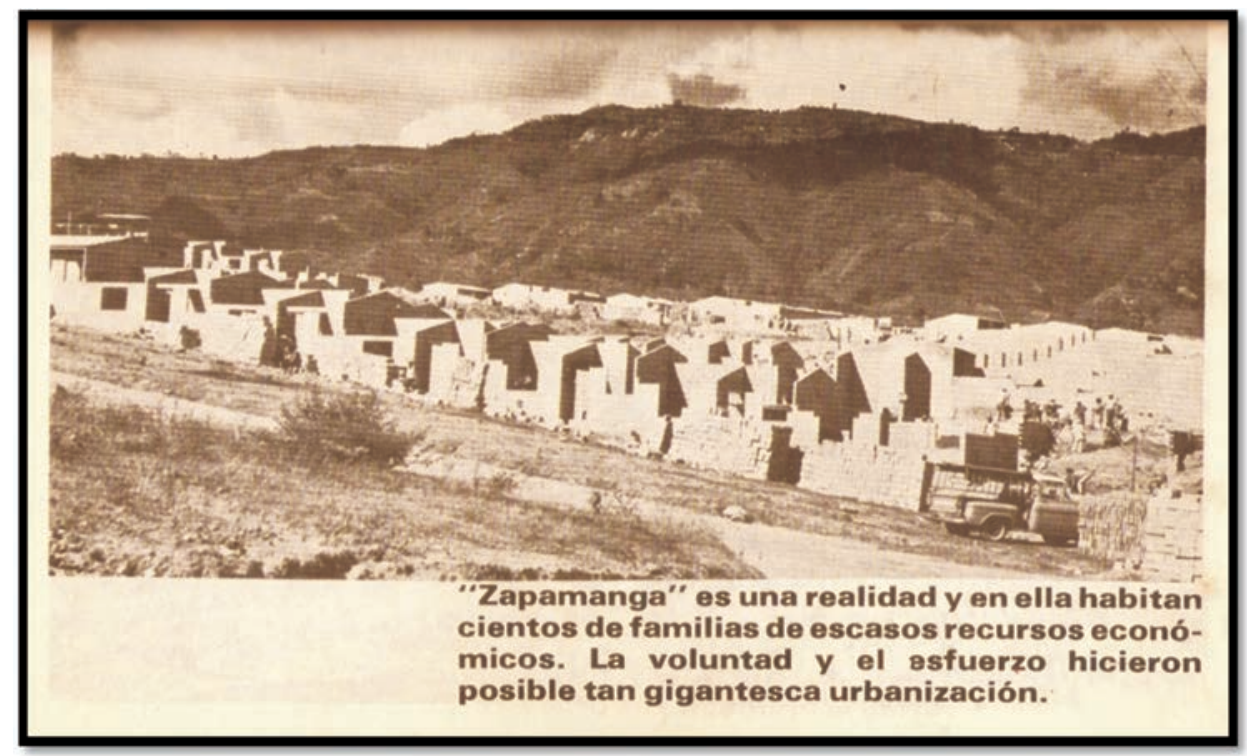




\section{ASPECTOS URBANÍSTICOS}

El sistema planteado en la urbanización, se denominó célula y estaba configurado en manzanas de alrededor de dieciocho (I8) viviendas pareadas, con una tipología de lote de $72 \mathrm{~m}^{2}(6 \times 12)$, hacia las esquinas se propuso una variedad tipológica de vivienda lo cual generaba una diferencia en las disposición final de la manzana.

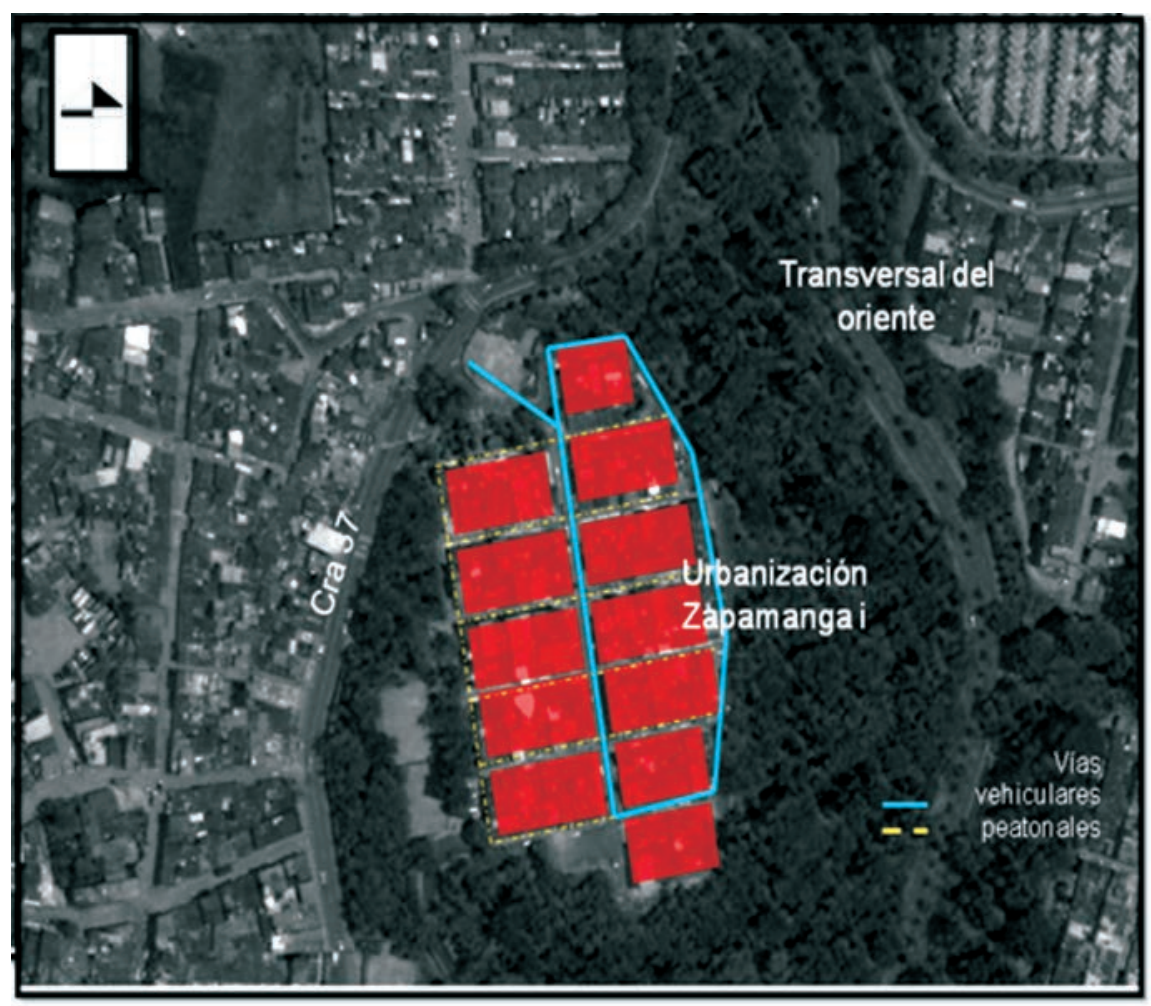

\section{ASPECTOS ARQUITECTÓNICOS}

El programa arquitectónico se basó en un área inicial construida, que equivale a $32,716 \mathrm{~m}^{2}$ con espacios multifuncionales. De igual manera el objetivo de este proyecto era lograr un desarrollo progresivo de las viviendas, se tenía como referente el lote que contaba con un área de $72 \mathrm{~m}^{2}$; para estos avances se previó en la construcción una cimentación de tres metros de profundidad, que permitiera levantar en el futuro la edificación sin ningún contratiempo. La vivienda se entregó en su primera etapa con un sistema constructivo tradicional, bloques de cemento que se elaboraban in situ, el fin era disminuir costos en la construcción, sin ningún tipo de friso, piso en cemento afinado y cubierta en teja ondulada de asbesto-cemento.
Imagen 3. Disposición de manzanas y vías Fuente: Fotografía satelital de Google Earth, Image 2010 Digital Globe, intervenida por la autora 


\section{PROGRAMA ARQUITECTÓNICO}

Cuadro 3. Programa arquitectónico relación espacios-lote

\begin{tabular}{|c|c|c|}
\hline ÁREA & Metros Cuadrados $\left(\mathbf{m}^{2}\right)$ & Porcentaje $(\%)$ \\
\hline Espacio múltiple & 17.332 & 24.07 \\
\hline Cocina & 6.922 & 9.61 \\
\hline W.C. & 1.703 & 2.365 \\
\hline Lavadero & 1.356 & 1.88 \\
\hline Patio & 16.558 & 22.9 \\
\hline Circulaciones & 2.850 & 3.958 \\
\hline TOTAL & 46,721 & 64.783 \\
\hline
\end{tabular}

Fuente: Elaborado por la autora

\section{MOMENTO 2004: DE LAS POLÍTICAS ESTATALES}

En el Plan de Desarrollo 2002-2006, implementado por el Gobierno Nacional en cabeza del Presidente Álvaro Uribe Vélez, las políticas de vivienda estaban enfocadas en contribuir al crecimiento económico del país y a la generación de empleo bajo criterios empresariales con responsabilidad social, para afrontar con eficiencia, los crecientes déficit cuantitativos y cualitativos. Se promovieron y fomentaron para ello esquemas de asociación mixta para la investigación y desarrollo en tecnologías en aumento de la productividad y mejoramiento de la calidad de interés social que permitiera aumentar las condiciones de acceso a la vivienda y un razonable aprovechamiento de los recursos, reconociendo las singularidades urbanoregionales del país ${ }^{8}$. La política habitacional en este período se entendía como constructora de equidad social, para lo cual el gobierno garantizaría la transparencia en la distribución de los recursos orientados a la población y las regiones en condiciones de pobreza. Para lograr la cobertura y eficacia en la ejecución de los programas, el gobierno delegó los procesos como se expresa en la siguiente gráfica:

Gráfico I. Estructura de Asociación para el Fomento de los Programas de Vivienda Fuente: Capacitación Política de Vivienda Nacional, Viceministerio de Vivienda y Desarrollo Territorial

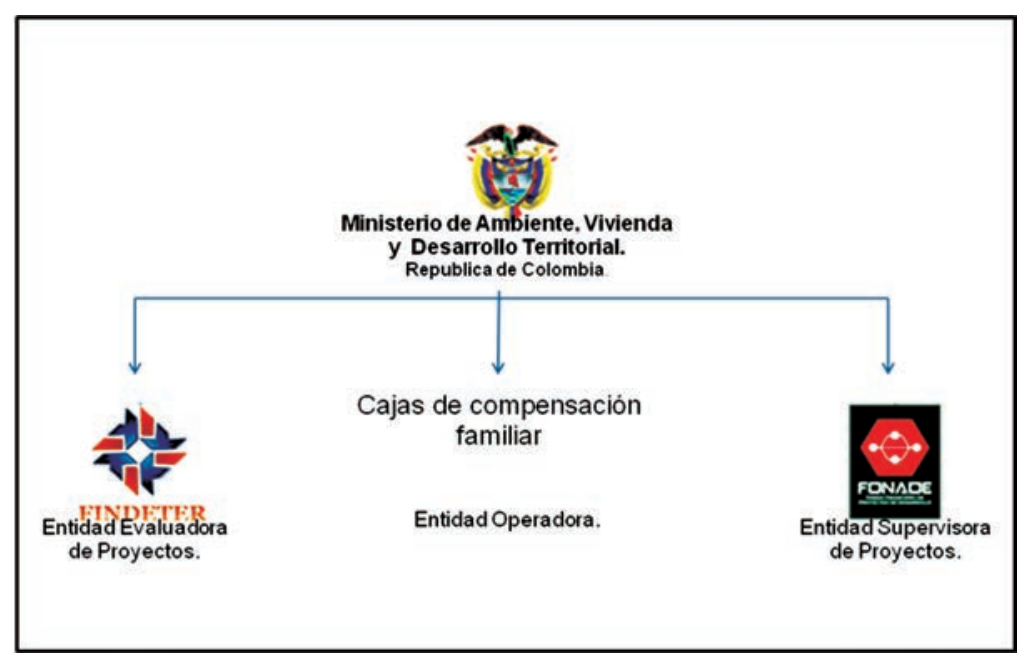

8 Ley 8 I2 de 2003, Plan de Desarrollo 2003-2006. Crecimiento económico sostenible y generación de empleo. Impulso a la vivienda. 
Funciones de la entidad evaluadora de proyectos: entidad encargada de la verificación del cumplimiento de los requisitos técnicos, jurídicos y financieros de los planes de vivienda de interés social; realizará acompañamiento a los oferentes para la formulación de proyectos de vivienda de interés social. El resultado de su labor se concreta en la expedición de certificados de elegibilidad.

Funciones de la entidad operadora: es la encargada de desarrollar procesos de divulgación, comunicación e información; recepción de solicitudes, verificación y revisión de la información; digitación, ingreso al RUP (Registro Único de Postulantes del Gobierno Nacional)

Pre-validación: seguimiento y verificación de los documentos para hacer efectivo el pago de los SFV, con el fin de garantizar la debida inversión de los recursos.

Funciones de la entidad supervisora de proyectos: es la encargada de supervisar la ejecución de los proyectos en los que se aplican subsidios de vivienda de interés social y que hayan solicitado pago anticipado del mismo.

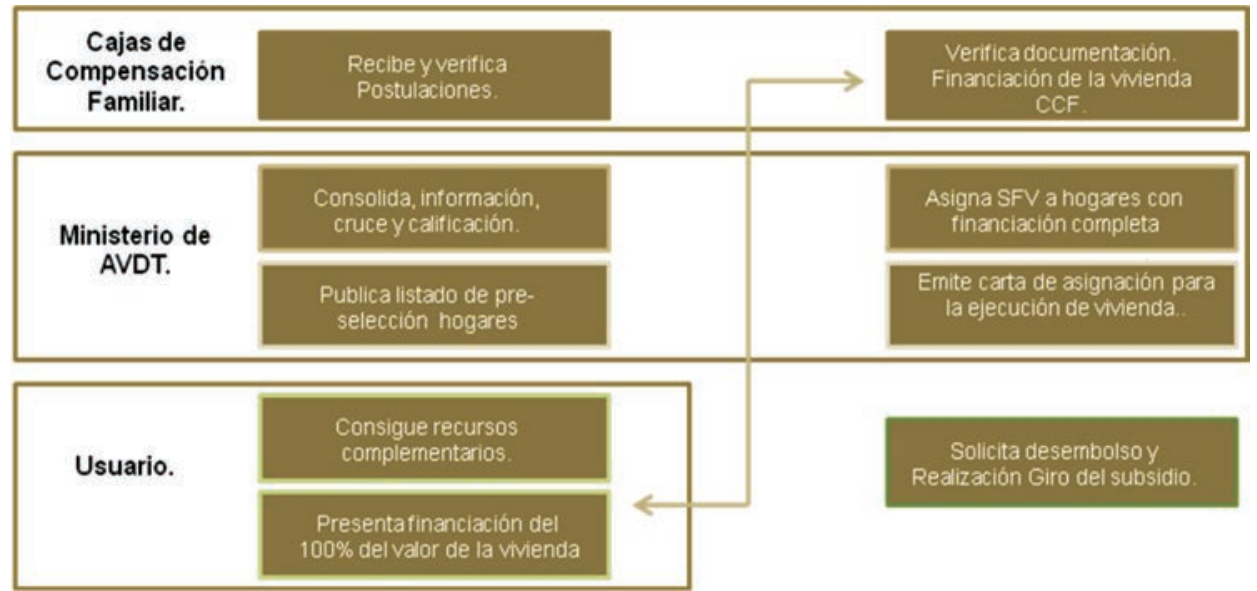

CRITERIOS PARA EL PROGRAMA DE ASIGNACIÓN DE SUBSIDIOS. VIVIENDA: SOLUCIONES AL ALCANCE DE TODOS. ESTRATEGIA PLAN NACIONAL DE DESARROLLO

En esta etapa se pretende optimizar el Programa de Subsidio Familiar de Vivienda a través de los siguientes mecanismos:

- Incorporar la definición de Vivienda de Interés Prioritario para focalizar recursos.

- Ajustar los montos de SFV así: i) para las CCF conforme a los ingresos del afiliado; ii) para Fonvivienda conforme al puntaje SISBEN.

- Fortalecer el SFV para mejoramiento de vivienda (mediante Bancos de Materiales) y los procesos de titulación masiva.

- Ajustar los procedimientos de supervisión e interventoría.

- Con el fin de estimular la oferta de vivienda para la población más vulnerable, las entidades públicas, solo podrán invertir recursos en VIP.
Gráfico 2. Proceso de Asignación del Subsidio Fuente: Capacitación Política de Vivienda Nacional, Viceministerio de Vivienda y Desarrollo Territorial. 
MINISTERIO DE AMBIENTE, VIVIENDA Y DESARROLLO TERRITORIAL: DECRETO 2060 DE 2004. POR EL CUAL SE ESTABLECEN NORMAS MÍNIMAS PARA VIVIENDA DE INTERÉS SOCIAL URBANA'

Cuadro 4. Normas mínimas de vivienda de interés social planteadas en el Decreto 2060 de 2004

\begin{tabular}{|c|c|c|c|}
\hline TIPO DE VIVIENDA & LOTE MÍNIMO & FRENTE MÍNIMO & AISLAMIENTO \\
\hline UNIFAMILIAR & $35 \mathrm{~m} 2$ & $3.50 \mathrm{~m} 2$ & $2.00 \mathrm{~m} 2$ \\
\hline BIFAMILIAR & $70 \mathrm{~m} 2$ & $7.00 \mathrm{~m} 2$ & $2.00 \mathrm{~m} 2$ \\
\hline MULTIFAMILIAR & $120 \mathrm{~m} 2$ & - & - \\
\hline
\end{tabular}

Fuente: Información disponible en Internet en: http://www.cntv.org.co

Se establecieron los porcentajes de cesiones urbanísticas gratuitas para el desarrollo de programas VIS Tipo I y 2 en un $25 \%$ del área neta urbanizable, se distribuyó para el espacio público entre el 15 y $20 \%$ del área neta urbanizable y para el equipamiento entre 5 y $10 \%$. De allí que la densidad habitacional aprovechable sería el resultado de aplicar las normas de lote mínimo y cesiones urbanísticas gratuitas sobre el predio objeto de desarrollo, calculándose de forma tal que pudiera generar el máximo número de soluciones posibles en las condiciones de precio de la vivienda que establecían las normas vigentes.

\section{PLAN DE ORDENAMIENTO TERRITORIAL DE FLORIDABLANCA}

El Plan de Ordenamiento Territorial de Floridablanca, es la herramienta de planificación que busca mejorar la calidad de vida de los habitantes, y proveer el desarrollo sustentable del territorio. Como mecanismo que define las zonas donde se ejecutarán los proyectos y el alcance de las mismas en el tema de Vivienda de Interés Social, designa unas áreas y políticas para el desarrolla de las viviendas (Ver cuadro 5.)

Cuadro 5. Oferta de suelo urbano para Vivienda de Interés Social en Floridablanca

\begin{tabular}{|l|c|c|c|c|c|}
\multirow{2}{*}{ ÁREA HOMOGÉNEA } & \multirow{2}{*}{$\begin{array}{c}\text { EXTENSIÓN } \\
\text { TOTAL }\end{array}$} & \multicolumn{2}{c|}{ USO DE VIVIENDA } & \multicolumn{2}{c}{ USO DE VIS } \\
\cline { 3 - 6 } & & Extensión & Porcentaje & Extensión & Porcentaje \\
\hline SENA & $231,30 \mathrm{Ha}$ & $127,21 \mathrm{Ha}$ & $55 \%$ & $44,52 \mathrm{Ha}$ & $35 \%$ \\
\hline La Cumbre & $162,40 \mathrm{Ha}$ & $73,08 \mathrm{Ha}$ & $45 \%$ & $7,30 \mathrm{Ha}$ & $10 \%$ \\
\hline Santana & $78,90 \mathrm{Ha}$ & $51,28 \mathrm{Ha}$ & $65 \%$ & $7,69 \mathrm{Ha}$ & $15 \%$ \\
\hline Ciudad Valencia-Lagos & $152,90 \mathrm{Ha}$ & $98,02 \mathrm{Ha}$ & $65 \%$ & $1,96 \mathrm{Ha}$ & $2 \%$ \\
\hline El Carmen & $79,60 \mathrm{Ha}$ & $47,76 \mathrm{Ha}$ & $60 \%$ & $19,10 \mathrm{Ha}$ & $40 \%$ \\
\hline Río Frío y Aranzoque & $312,50 \mathrm{Ha}$ & $203,12 \mathrm{Ha}$ & $65 \%$ & $20,31 \mathrm{Ha}$ & $10 \%$ \\
\hline TOTAL & $\mathbf{1 . 0 1 7 , 6 0 ~ H a}$ & $\mathbf{6 0 0 , 4 7 ~ H a}$ & $\mathbf{5 9 \%}$ & $100,88 \mathrm{Ha}$ & $19 \%$ \\
\hline
\end{tabular}

Fuente: Equipo CER-UIS, Plan de Ordenamiento Territorial de Floridablanca

9 Diario Oficial No 45.59025 de junio de 2004, Ministerio de Ambiente, Vivienda y Desarrollo Territorial. 
El Plan de Vivienda de Interés Social busca definir los terrenos aptos para urbanizar, un sistema de consecución de materiales de bajo costo en la medida de las posibilidades subsidiado por el Municipio, entes territoriales e internacionales y gestionar un sistema de financiación que garantice el acceso a la comunidad.

Como políticas del Plan de Vivienda se contempla garantizar un entorno digno para las soluciones de vivienda, a este respecto, es preciso anotar que Floridablanca es el asiento de la fuerza de trabajo de buena parte del Área Metropolitana y como tal ocupan sus viviendas operarios y trabajadores calificados y no calificados, artesanos, profesionales y servidores de la más variada cantidad de oficios. Por ello, la vivienda debe procurar un sitio de trabajo a estas personas, fortalecer las calidades habitacionales de la ciudad y actuar como generadora de autoempleo. El programa económico del POT prevé acciones de creación de empresa (microempresa, fami-empresa, empresa asociativa), iniciativas que pueden ocurrir dentro de la vivienda que contribuyen a crear ahorros de tiempo en desplazamientos, de dinero en transportes de mercancías y de trabajadores y auto - subsidiariedad de servicios públicos y de arriendos. Hacer productiva la vivienda también significa configurar una arquitectura que facilite las actividades de trabajo y dormitorio, fortalecer la creación de espacio público como complemento de equipamiento comunal y un mejoramiento sustancial de la calidad de vida.

Además de los programas de financiación de vivienda y las iniciativas de la Nación en la materia, el Municipio debe tener su propia fuente de financiamiento de la vivienda de bajo costo. El sistema de crédito rotativo a través de un fondo especializado de vivienda garantiza el acceso de todos a los programas habitacionales. Por otra parte, la gestión conjunta entre el Municipio y el sector privado debe conducir a conseguir precios más asequibles y condiciones más favorables en la calidad de la construcción; así mismo, el Municipio debe buscar otorgar subsidios (distintos de los de la Nación) a los sectores de la comunidad menos favorecidos con el objeto de garantizar el acceso a la vivienda.

\section{SISTEMAS DE FINANCIACIÓN Y ADJUDICACIÓN}

SUBSIDIO FAMILIAR DE VIVIENDA: Es un aporte en dinero o en especie (terreno), que otorga el gobierno nacional por una sola vez al beneficiario, que constituye un complemento de su ahorro, su crédito u otros aportes para facilitarle la adquisición de una vivienda nueva, la construcción de una vivienda en sitio propio o el mejoramiento de una vivienda de interés social de su propiedad. Es el gobierno nacional a través del Ministerio de Ambiente, Vivienda y Desarrollo Territorial, y las cajas de compensación familiar, quien otorga el subsidio para vivienda urbana, pudiéndolo solicitar, los hogares cuyos ingresos provengan de una actividad informal o independiente ${ }^{10}$. Se contemplan como requisitos para solicitar el subsidio ante FONVIVIENDA, tener conformado un grupo familiar de dos o más personas y contar con ingresos totales mensuales del grupo familiar no superiores a 4 salarios mínimos mensuales provenientes de una actividad informal o independiente.

Se establece en esta política que el subsidio de vivienda se puede emplear en caso de adquirir vivienda nueva, construir en sitio propio, mejorar la existente y en caso de arrendamiento o compra de vivienda usada" como se explica a continuación:

10 Se entiende por hogar el conformado por los cónyuges, las uniones maritales de hecho y/o el grupo de personas unidas por vínculos de parentesco hasta tener tercer grado de consanguinidad, segundo de afinidad y primero civil, que compartan un mismo espacio habitacional.

II Con respecto al arrendamiento o la vivienda usada, se establece la condicionante de población desplazada, atentados terroristas y desastres naturales. 
Vivienda Nueva: Es el proceso por el cual el beneficiario de un subsidio familiar adquiere su solución de vivienda dentro de los planes elegibles y conforme a los requisitos y procedimientos establecidos en la Ley 3 de 1991 y en el Decreto 975 de 2004; es decir, mediante firma de escritura y registro de la misma en la Oficina de Instrumentos Públicos.

Construcción en Sitio Propio: Es el proceso por el cual el beneficiario del subsidio accede a una vivienda de interés prioritario mediante la edificación de la misma en un sitio de su propiedad que puede ser un lote, una terraza o una cubierta de losa.

Mejoramiento: Permite superar una o varias de las carencias básicas de la vivienda siempre y cuando esta pertenezca o tenga la posesión en uno de los miembros del hogar postulado y vivan en ella (deficiencias en la estructura principal, cimientos, muros o cubierta; carencia o vetustez de redes secundarias y acometidas domiciliarias de acueducto y alcantarillado; carencia o vetustez de baños y/o cocina; existencia de pisos en tierra o en materiales inapropiados y construcción en materiales provisionales tales como latas, tela asfáltica y madera de desecho)

\section{ANÁLISIS DEL PROYECTO URBANIZACIÓN JUAN PABLO II}

Imagen 4. Localización de la Urbanización Juan Pablo II, en Floridablanca Fuente: Mapa Urbano. Plan de Ordenamiento Territorial Floridablanca.

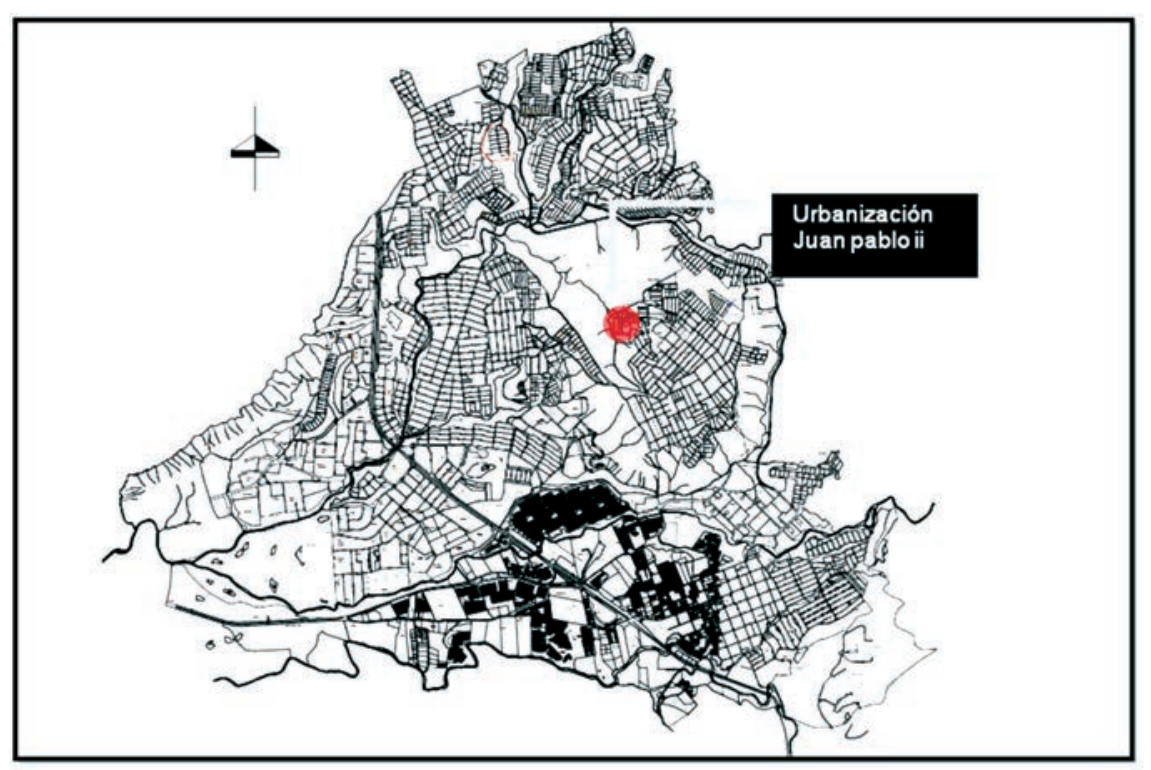

La Urbanización Juan Pablo II, se encuentra ubicada en el Municipio de Floridablanca, en el sector Aguas Claras, del barrio La Cumbre. Se trata de un proyecto llevado a cabo en etapas por el Banco Inmobiliario de Floridablanca, que buscaba solucionar los problemas de vivienda de 500 personas en estado de vulnerabilidad producto del conflicto armado y desastres naturales, ubicadas en asentamientos emplazados en zonas de alto riesgo sobre la Transversal Oriental, en el sector de Bucarica, así como también aquellas que carecían de este bien. 


\section{DESCRIPICIÓN DEL PROYECTO}

El BIF de acuerdo a los lineamientos expuestos en el Decreto 2060 de 2004, ubicó un lote de 2,537.46I hectáreas, hizo una subdivisión predial que dio como resultado un lote de $35 \mathrm{~m} 2$. La ubicación del terreno, se encuentra en las zonas destinadas en el Plan de Ordenamiento Territorial.

Cuadro 6. Ficha Técnica de Análisis del Proyecto

\begin{tabular}{|c|c|c|c|c|}
\hline \multicolumn{5}{|c|}{ CARACTERÍSTICAS } \\
\hline VARIABLE & INDICADOR & \multicolumn{3}{|c|}{ INFORMACIÓN } \\
\hline \multirow{10}{*}{ DATOS GENERALES } & Localización & \multicolumn{3}{|c|}{$\begin{array}{l}\text { Comuna: La Cumbre-El Carmen Municipio } \\
\text { Floridablanca, Santander }\end{array}$} \\
\hline & Destinación Zona & \multicolumn{3}{|c|}{ Vivienda de Interés Social } \\
\hline & Ubicación Relativa & \multicolumn{3}{|c|}{$\begin{array}{l}\text { Calle I4ID con Carrera } 46 \text { Costado } \\
\text { Nororiental de Florida Campestre }\end{array}$} \\
\hline & Superficie & \multicolumn{3}{|c|}{$25374,61 \mathrm{~m} 2$} \\
\hline & Antigüedad & \multicolumn{3}{|l|}{5 años } \\
\hline & Población & \multicolumn{3}{|c|}{500 personas } \\
\hline & Cantidad de Manzanas & \multicolumn{3}{|l|}{4} \\
\hline & $\begin{array}{l}\text { Cantidad de Lotes por } \\
\text { manzana }\end{array}$ & \multicolumn{3}{|c|}{$\begin{array}{lcl}\text { Manzana 1. } & 3 & \text { Manzana 3. } 12 \\
\text { Manzana 2. } & 12 & \text { Manzana 4. } 54\end{array}$} \\
\hline & Cantidad de Viviendas & \multicolumn{3}{|c|}{81} \\
\hline & Cantidad de Familias & \multicolumn{3}{|l|}{81} \\
\hline \multirow{5}{*}{ ÍNDICES GENERALES } & Composición Familiar & \multicolumn{3}{|c|}{ 5-7 personas } \\
\hline & \multirow{2}{*}{ Hacinamiento } & \multicolumn{3}{|c|}{ Habitantes/ Familias 5-7 } \\
\hline & & \multicolumn{3}{|c|}{ Familias/Viviendas I -2 } \\
\hline & \multirow{2}{*}{ Densidad } & \multicolumn{3}{|c|}{ Habitantes/Hectáreas 197} \\
\hline & & \multicolumn{3}{|c|}{ Lotes/Hectáreas 32} \\
\hline \multirow{4}{*}{$\begin{array}{l}\text { DISEÑO Y } \\
\text { APROBACIONES }\end{array}$} & Planos Topográficos & $\mathrm{Si} \quad \mathrm{x}$ & $\mathrm{N}$ & \\
\hline & Planos Urbanísticos & $\mathrm{Si}$ & Nc & \\
\hline & Planos de Servicios & \multicolumn{3}{|l|}{$\mathrm{Si} \quad \mathrm{x}$} \\
\hline & Decretos Reglamentarios & \multicolumn{3}{|l|}{$\mathrm{Si} \quad \mathrm{x}$} \\
\hline \multirow{6}{*}{ INFRAESTRUCTURA } & Vías & \multicolumn{3}{|c|}{ Si, planteadas } \\
\hline & Agua Potable & \multicolumn{3}{|l|}{$\mathrm{Si}$} \\
\hline & Aguas Negras & $\mathrm{Si}$ & & \\
\hline & Energía & $\mathrm{Si}$ & & \\
\hline & Gas & $\mathrm{Si}$ & & \\
\hline & Teléfono & No & & \\
\hline ESTADO DE & Cómo fue entregada & $\begin{array}{l}\text { Primera fas } \\
\text { progresivo }\end{array}$ & el de & rrollo \\
\hline LA VIVIENDA & Mejoramiento & $\begin{array}{l}\text { De acuerd } \\
\text { de la famili }\end{array}$ & a dis & nibilidad presupuestal \\
\hline & Comercio & Si, tiendas & & \\
\hline & Educación & No & & \\
\hline & Salud & No & & \\
\hline & Religiosos & No & & \\
\hline & $\begin{array}{l}\text { Socio-Cultural- } \\
\text { Recreativos }\end{array}$ & Si, Comed & fant & \\
\hline EQUIPAMIENTO & Deportivos & No & & \\
\hline COMUNITARIO & Transporte & No & & \\
\hline & Recolección de Basuras & No & & \\
\hline & Nomenclatura & $\mathrm{Si}$ & & \\
\hline & Seguridad & Vecinal & & \\
\hline
\end{tabular}

Fuente: Elaborado por la autora 


\section{ASPECTOS SOCIALES}

La ola invernal del año 2005 produjo deslizamientos e inundaciones en el Municipio de Floridablanca, principalmente en la invasión ubicada en la Transversal Oriental a la altura del sector de Bucarica, 65 familias perdieron sus viviendas improvisadas. Esta problemática obligó a que la administración municipal, gestionara con el Banco Inmobiliario de Floridablanca este proyecto de Vivienda de Interés Social, para brindar un hogar a estas familias y a otras 16 víctimas del conflicto armado. El programa contó con el acompañamiento de los gobiernos nacional, departamental y municipal, quienes aportaron dinero para subsidiar el proyecto, de forma tal que los beneficiarios no tuvieron que pagar por la casa, pero sí por el alcantarillado y la escrituración.

\section{ASPECTOS URBANÍSTICOS}

El proyecto fue planeado para desarrollarse por etapas, en donde la inicial correspondía a viviendas unifamiliares implantadas en un lote de 35 metros cuadrados, ubicadas en un modelo urbano de casas en hilera; debido a la complejidad del lote se realizan adecuaciones para evitar el riesgo de inundación por parte de las fuentes hídricas cercanas. Tipológicamente los predios se encuentran ubicados en manzanas y supermanzanas. Los perfiles viales, son de carácter peatonal y vehicular.

Imagen 5. Disposición de manzanas y vías. Fuente: Fotografía satelital de Google Earth, Image 2010 Digital Globe, intervenida por la autora

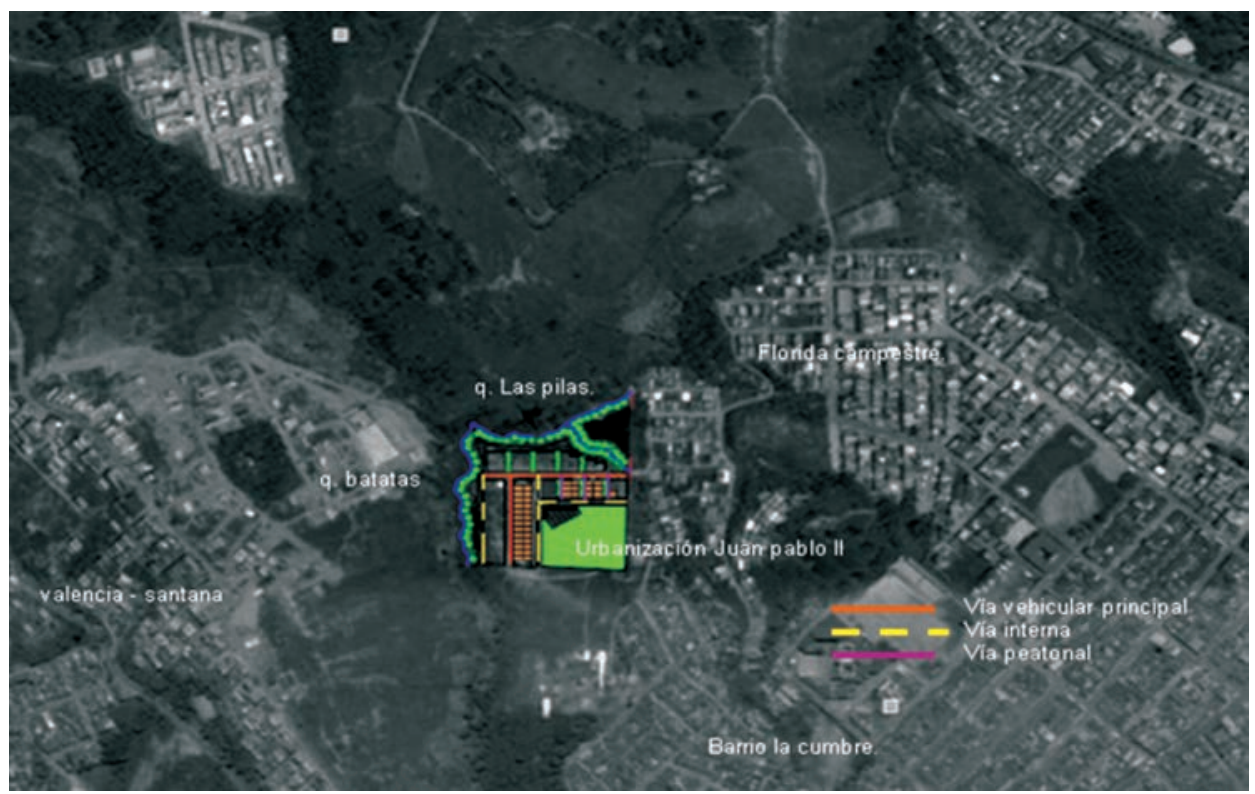

\section{ASPECTOS ARQUITECTÓNICOS}

El programa de áreas se desarrolla habida cuenta de la multifuncionalidad de los espacios que permiten un desarrollo progresivo. Los términos de referencia se ajustan a la normativa vigente que proporcionan unas condiciones mínimas de ejecución y entrega de la obra. En el primer piso se dispuso la sala comedor, cocina con enchape en la zona húmeda y escalera prefabricada, patio de ropas, fachada con mampostería a la vista, piso en concreto rústico, puerta ventana principal y puerta del patio; en el segundo alcobas con piso rústico, baño lavamanos, sanitario, ducha enchapada en zona húmeda y ventana en la fachada principal. 
Cuadro 7: Programa arquitectónico relación espacios-lote

\begin{tabular}{|c|c|c|}
\hline ÁREA & Metros Cuadrados $\left(\mathrm{M}^{2}\right)$ & Porcentaje (\%) \\
\hline Cocina & $2,420 \mathrm{~m}^{2}$ & $6.91 \%$ \\
\hline Sala & $8,052 \mathrm{~m}^{2}$ & $23.00 \%$ \\
\hline Comedor & $7,594 \mathrm{~m}^{2}$ & $21,69 \%$ \\
\hline W.C. & $3,472 \mathrm{~m}^{2}$ & $9.92 \%$ \\
\hline Patio & $6,563 \mathrm{~m}^{2}$ & $18.75 \%$ \\
\hline Alcobas & $17,718 \mathrm{~m}^{2}$ & $50,62 \%$ \\
\hline Circulaciones+ Escaleras & 4,438 & $12,68 \%$ \\
\hline TOTAL & 51,972 & $143.57 \%$ \\
\hline
\end{tabular}

Fuente: Elaborado por la autora

\section{ANÁLISIS COMPARATIVO}

Este análisis se desarrolló con referencia a los factores que intervinieron en el desarrollo de la vivienda y que determinaron la calidad de la misma. Para ello se utilizaron herramientas de recopilación y verificación de información, encaminadas a observar el progreso de la vivienda y su entorno inmediato. Por otra parte, los dos proyectos presentan características comunes y divergentes, que permiten generar variables e indicadores de cualificación y cuantificación, útiles para determinar si la vivienda cumplía o no con normas mínimas de habitabilidad que promovieran el desarrollo de las familias que las ocupan.

\section{FACTOR SOCIOLÓGICO}

Para desarrollar esta categoría se realizaron visitas a las urbanizaciones y entrevistas con residentes que han estado en los procesos de inicio y consolidación de las mismas, se efectúo una encuesta a los beneficiarios de la Urbanización Juan Pablo II, que permitió conocer características actuales del proyecto, no se aplicó a Zapamanga I porque la urbanización ha experimentado grandes transformaciones en las viviendas inicialmente entregadas.

Cuadro 8. Desarrollo variable factor social

\begin{tabular}{|l|l|}
\hline \multicolumn{2}{|c|}{ Características de los beneficiarios de la Vivienda de Interés Social } \\
\hline & $\begin{array}{l}\text { Si bien en la década del } 70 \text { el problema del desplazamiento forzado era una de las } \\
\text { razones de migración a los centros urbanos, la característica preponderante de los } \\
\text { beneficiarios de este programa de vivienda fue el mejoramiento de la calidad de vida } \\
\text { para personas de escasos recursos que conformaron nuevos núcleos familiares y que } \\
\text { necesitaban un lugar para comenzar su familia. En promedio el número de personas } \\
\text { que conforman el grupo familiar de este programa oscila entre } 4 \text { y } 5 \text { miembros. }\end{array}$ \\
\hline $\begin{array}{l}\text { Urbanización Zapamanga } \\
\text { I Etapa }\end{array}$ & $\begin{array}{l}\text { El proyecto estaba enfocado en dar solución de vivienda a un grupo de personas } \\
\text { con problemas de desplazamiento por fenómenos naturales y víctimas del conflicto } \\
\text { armado, que después de un largo proceso de espera para obtener una vivienda } \\
\text { lograron acceder a este programa subsidiado por el gobierno. En promedio el } \\
\text { número de personas que conforman el grupo familiar de este programa oscila entre } \\
5 \text { y } 7 \text { miembros. }\end{array}$ \\
\hline Urbanización Juan Pablo II
\end{tabular}

Fuente: Elaborado por la autora 


\section{EL ALCANCE DE LA SOLUCIÓN DE VIVIENDA}

Tomado como antecedente el indicador anterior y la vivienda actual construida, se observa si esta cumplió con las expectativas de sus usuarios, ya que no basta sólo con poner un techo y unas paredes para resguardar a las personas, sino que en este espacio se pueda consolidar el núcleo familiar, que permita realizar las actividades básicas para ello. Igualmente el entorno inmediato genera situaciones que benefician o perjudican el desarrollo de las familias.

Cuadro 9. Desarrollo variable factor social

\begin{tabular}{|l|l|}
\hline \multicolumn{2}{|c|}{ Alcance de la solución de vivienda } \\
\hline $\begin{array}{l}\text { Urbanización } \\
\text { Zapamanga }\end{array}$ & $\begin{array}{l}\text { Este programa fue uno de los primeros en implementar el sistema de autoconstrucción, lo cual } \\
\text { permitió que las familias se vincularan directamente con el desarrollo de su vivienda, creándose } \\
\text { así un sentido de pertenencia. El éxito de este proyecto es que contaba con un área de lote de } \\
72 \mathrm{~m} 2 \text { y buscaba que las familias hicieran un desarrollo progresivo de su vivienda de acuerdo a } \\
\text { los ingresos y disposiciones de la misma. }\end{array}$ \\
\hline $\begin{array}{l}\text { Urbanización } \\
\text { Juan Pablo II }\end{array}$ & $\begin{array}{l}\text { Por medio de subsidios estatales les fue posible a estos beneficiarios obtener su casa, aunque esta } \\
\text { proyecto también se habla de un desarrollo progresivo, el cual es mínimo debido a que el lote sólo } \\
\text { cuenta con 35m2, y las modificaciones que se permiten son reducidas. Además se observó que } \\
\text { hay un fraccionamiento del núcleo familiar, debido a que hay que reacomodar a los integrantes de } \\
\text { modo que no se presenten fricciones entre ellos. Ej. Primer Piso duermen el papá con los hijos } \\
\text { varones, y en el segundo nivel la mamá y las hijas. }\end{array}$ \\
\hline
\end{tabular}

Fuente: Elaborado por la autora

\section{FACTOR ECONÓMICO}

\section{BIEN NECESARIO: LA VIVIENDA}

En la actualidad el país presenta un déficit de 1.300 .000 viviendas, para el caso de Floridablanca, en cuanto al déficit cuantitativo se presenta en 6.783 y en el cualitativo en 3.84I. Estas cifras marcan un referente sobre el alto porcentaje de familias que requieren de este bien, de allí que sea importante analizar los costos de la vivienda y la forma como se adquiere, para lograr soluciones efectivas y rentables ${ }^{12}$.

Cuadro 10. Desarrollo variable factor económico

\begin{tabular}{|l|l|}
\hline \multicolumn{2}{|c|}{ Bien Necesario: La Vivienda } \\
\hline Zapamanga & $\begin{array}{l}\text { Este proyecto fue ofertado por el ICT en 1976, como un programa de vivienda popular de } \\
\text { autoconstrucción asistida técnicamente por personal del ICT. La vivienda tuvo un costo de } \\
\$ 123.000, \text { con una cuota inicial de } 9.000 \text { pesos y luego cuotas de } 68 \text { pesos en adelante. La } \\
\text { construcción de la urbanización se realizó por parte de los usuarios y personal técnico del ICT, } \\
\text { los usuarios tenín el compromiso de trabajar sábados y domingos y la asignación de viviendas } \\
\text { se efectuó después de haber culminado completamente la construcción, por medio de un } \\
\text { sorteo. Este programa redujo los costos de la vivienda y permitió que las personas tuvieran } \\
\text { recursos para su mejoramiento. }\end{array}$ \\
\hline Juan Pablo II & $\begin{array}{l}\text { Este proyecto fue ofertado por el BIF entre los años } 2005 \text { y 2008, como un programa de } \\
\text { vivienda interés social subsidiada. La vivienda tuvo un costo de } \$ 18.143 .818 .23 \text { que fue } \\
\text { cubierto por el subsidio otorgado y los beneficiarios tuvieron que pagar por las escrituras el } \\
\text { valor de } \$ 90.000 \text { y por el alcantarillado } \$ 100.000 .\end{array}$ \\
\hline
\end{tabular}

Fuente: Elaborado por la autora

12 Departamento Administrativo Nacional de Estadísticas, DANE, Censo 2005. 


\section{FACTOR POLÍTICO}

\section{CARACTERIZACIÓN DE LAS POLÍTICAS DE VIVIENDA}

Cada gobierno presenta una serie de lineamientos políticos, económicos y técnicos que establecen el desarrollo de programas de vivienda, de igual manera como está contemplado en la Constitución Política, en el Art. 5I, en el cual se dispone que el Estado:

"promoverá planes de vivienda de interés social, sistemas adecuados de financiación a largo plazo y formas asociativas de ejecución de estos programas de vivienda“"

La intervención del Estado es determinante en los resultados de estos proyectos.

Cuadro II. Desarrollo variable factor político

\begin{tabular}{|l|l|}
\multicolumn{2}{|c|}{ Caracterización de las Políticas de Vivienda } \\
\hline $\begin{array}{l}\text { Zapamanga } \\
\text { I Etapa }\end{array}$ & $\begin{array}{l}\text { El gobierno de la época, tenía un enfoque asistencialista, que buscaba llegar directamente al usuario } \\
\text { que carećía de vivienda. Lo hacía fortaleciendo las entidades en cada una de las facetas que un } \\
\text { proyecto necesita para desarrollarse, desde los inicios con la proyección y en la ejecución con } \\
\text { los diseños y la construcción. Esto permitió que el ICT contara con recursos tanto administrativos } \\
\text { como económicos para desarrollarlo. }\end{array}$ \\
\hline Juan Pablo II & $\begin{array}{l}\text { El comienzo del siglo XXI supone para el país entrar activamente en el mundo globalizado para } \\
\text { poder tener un desarrollo integral óptimo, es así como el Gobierno toma directrices de carácter } \\
\text { capitalista y tecnócrata para entrar a competir en estos desafíos de expansión económica. Para } \\
\text { el caso de la vivienda de interés social, estos lineamientos cobran importancia ya que hace que } \\
\text { haya un cambio trascendental en estos programas. }\end{array}$ \\
\hline
\end{tabular}

Fuente: Elaborado por la autora

\section{EFECTOS DE LAS POLÍTICAS}

Dos tipos de gobierno con características diversas, propusieron proyectos con lineamientos disímiles, tanto en los aspectos positivos como en los negativos, de allí que el análisis pretende mostrar las situaciones resultantes de las políticas establecidas tanto en 1972 como en 2004.

Cuadro 12. Desarrollo variable factor político

\begin{tabular}{|c|c|}
\hline \multicolumn{2}{|r|}{ Efectos de las Políticas de vivienda implementados en los dos períodos } \\
\hline $\begin{array}{l}\text { Zapamanga } \\
\text { I Etapa }\end{array}$ & $\begin{array}{l}\text { El ICT, con el aval del gobierno desde el punto de vista económico, pudo generar proyectos de } \\
\text { vivienda integrales, como es el caso de esta urbanización. Inicialmente el Instituto buscaba lotes en } \\
\text { las afueras del casco urbano antiguo (manzanas cercanas al parque principal) para poder desarrollar } \\
\text { el proyecto, actuaba como un colonizador, ya que contaba con los recursos para llevar hasta esos } \\
\text { lugares la infraestructura. }\end{array}$ \\
\hline Juan Pablo II & $\begin{array}{l}\text { La política nacional está dirigida a comisionar el tema de la vivienda, por eso delega el desarrollo de } \\
\text { los proyectos a diferentes entidades descentralizadas para que los lleven a cabo. De igual manera fija } \\
\text { unos parámetros iniciales, como es el de los metros cuadrados por lote para una vivienda, así como } \\
\text { también faculta a las administraciones locales para que dispongan los lugares donde se van a llevar a a } \\
\text { cabo los proyectos. Claro ejemplo de ello es esta urbanización, que comienza su proyección desce } \\
\text { la Alcaldía, con los estudios de oportunidad y conveniencia que indican la viabilidad del proyecto, } \\
\text { luego tiene que dirigirse a la Administración Nacional y Departamental para que dispongan de un } \\
\text { presupuesto que permita su realización. El proceso vuelve a la Secretaría de Planeación Municipal } \\
\text { que a través del POT indica dónde se debe ejecutar. Posteriormente se traslada el proyecto al BIF } \\
\text { donde se encargan de coordinar los diseños urbanos, arquitectónicos, los subsidios junto con las } \\
\text { cajas de compensación y, finalmente, crea un consorcio con una constructora particular para que } \\
\text { se ejecute el proyecto. }\end{array}$ \\
\hline
\end{tabular}

Fuente: Elaborado por la autora 


\section{FACTOR URBANÍSTICO}

\section{MORFOLOGÍA URBANA (UBICACIÓN Y ACCESIBILIDAD)}

Los proyectos de vivienda de interés social se han caracterizado por estar ubicados en la periferia de los centros urbanos, lo cual genera características precisas que establecen parámetros que miden la calidad de vida.

Cuadro 13. Desarrollo variable factor urbanístico

\begin{tabular}{|c|c|}
\hline \multicolumn{2}{|r|}{ Morfología Urbana (Ubicación y Accesibilidad) } \\
\hline $\begin{array}{l}\text { Urb. Zapamanga I } \\
\text { Etapa }\end{array}$ & $\begin{array}{l}\text { La localización de proyecto obedece a una determinación del ICT que tenía como objetivo solucionar } \\
\text { el déficit habitacional, por eso planeaba varias etapas para cada proyecto, ubicándolo en la periferia del } \\
\text { Municipio. Sin embargo, el Instituto, se encargaba de construir vías y hacer las gestiones pertinentes para } \\
\text { que las rutas de transporte público llegaran al sector. El diseño urbano estaba orientado a cumplir con } \\
\text { una densidad estimada de } 35 \text { y } 75 \text { viviendas por Ha. sobre la base de lotes de } 80 \mathrm{~m}^{2} \text {. De igual manera } \\
\text { se dejaban planteadas las áreas de Cesión para el equipamiento comunitario. }\end{array}$ \\
\hline Urb. Juan Pablo II & $\begin{array}{l}\text { Su ubicación está establecida por el Plan de Ordenamiento Territorial de Floridablanca que indica que } \\
\text { la Comuna La Cumbre - El Carmen, son las zonas donde se realizan proyectos de Vivienda de Interés } \\
\text { Social. El diseño urbano está a cargo del BIF, que busca el mejor aprovechamiento del lote y, de igual } \\
\text { manera, acata la normativa nacional de lotes de } 35 \mathrm{~m}^{2} \text {. Una problemática del sector es el difícil acceso } \\
\text { que imposibilita la llegada de vehículos. }\end{array}$ \\
\hline
\end{tabular}

Fuente: Elaborado por la autora

\section{EVOLUCIÓN DEL ÁREA URBANIZADA}

Es un aspecto importante, ya que la proyección de los sectores a corto, mediano o largo plazo, mejora sustancialmente la calidad de vida de sus residentes, sin embargo, hay que anotar que hay situaciones que contribuyen y alteran el desarrollo progresivo de los sectores.

Cuadro 14. Desarrollo variable factor urbanístico

\begin{tabular}{|l|l|}
\hline \multicolumn{2}{|c|}{ Evolución del área urbanizada } \\
\hline Urb. Zapamanga I Etapa & $\begin{array}{l}\text { Las necesidades y el trabajo comunitario han hecho que este sector haya tenido una } \\
\text { evolución favorable. En la actualidad las áreas que se habían dejado de cesión para } \\
\text { los equipamientos ya han sido utilizadas y se han realizado gracias a la voluntad y el } \\
\text { apoyo comunal con las administraciones locales. }\end{array}$ \\
\hline Urb. Juan Pablo II & $\begin{array}{l}\text { Actualmente el desarrollo urbano no ha sido culminado, vías y senderos peatonales } \\
\text { se encuentran todavía en obra. En cuanto al equipamiento comunitario todavía no } \\
\text { se ha desarrollado. Toda la infraestructura de salud, educación, recreación, religión y } \\
\text { transporte debe ser suplida por el Barrio La Cumbre. }\end{array}$ \\
\hline
\end{tabular}

Fuente: Elaborado por la autora

\section{FACTOR ARQUITECTÓNICO: ESPECIFICACIONES CONSTRUCTIVAS}

En esta variable se observaron los términos de referencia de la entrega de las viviendas en su primera etapa. 
Cuadro 15. Desarrollo variable factor arquitectónico

\begin{tabular}{|l|l|}
\hline \multicolumn{2}{|c|}{ Especificaciones constructivas } \\
\hline $\begin{array}{l}\text { Zapamanga I } \\
\text { Etapa }\end{array}$ & $\begin{array}{l}\text { La autoconstrucción permitió que se implementara un sistema para producir bloques de } \\
\text { cemento In Situ, que para la época era una alternativa novedosa que bajaba notablemente los } \\
\text { costos de transporte y costo del material. La idea de desarrollo progresivo de estas viviendas, } \\
\text { marcó un criterio para la entrega de las casas ya que se otorgaban en obra negra, los usuarios } \\
\text { se encargaban del mejoramiento y modificación de acuerdo a sus intereses y/o presupuestos. }\end{array}$ \\
\hline Juan Pablo II & $\begin{array}{l}\text { La construcción se realizó por parte de la Unión Temporal Villa Carolina, encargada de entregar } \\
\text { la primera etapa, un módulo de vivienda de 51,972m2, de la siguiente manera: estructura en } \\
\text { concreto, muros en mampostería HIO sin frisar, piso rústico, baños y cocina con enchape } \\
\text { sólo en la parte húmeda, puertas y ventanas metálicas. La cocina con mesón con friso y teja } \\
\text { con asbesto cemento. Cabe señalar que más de 20 viviendas no fueron entregadas con el área } \\
\text { completa, y sin accesorios como lavamanos, lavaplatos, sanitarios y lavadero. Estos tuvieron } \\
\text { que ser comprados por los habitantes. }\end{array}$ \\
\hline
\end{tabular}

Fuente: Elaborado por la autora

\section{DIMENSIONAMIENTO ESPACIAL (CONFORT, HIGIENE)}

La evaluación de los espacios analizados si responden a las funciones que en ellos se realizan, y poseen condiciones de iluminación, ventilación.

Cuadro 16. Desarrollo variable factor arquitectónico

\begin{tabular}{|l|l|}
\hline \multicolumn{2}{|c|}{ Dimensionamiento Espacial (Confort, higiene) } \\
\hline Zapamanga I Etapa & $\begin{array}{l}\text { La espacialidad inicial era limitada, ya que el área construida era mínima y los espacios } \\
\text { tendían a ser multifuncionales. La ventaja radicaba en el área de lote de } 72 \mathrm{~m}^{2} \text {, que admitía } \\
\text { adecuaciones, incluso la cimentación permitía la elevación de la edificación. }\end{array}$ \\
\hline Juan Pablo II & $\begin{array}{l}\text { Los espacios de estas viviendas ya están definidos y no permiten mayores modificaciones } \\
\text { en áreas, y aunque se habla de un desarrollo progresivo y de futuras ampliaciones, es } \\
\text { inconsistente ya que por el área mínima del lote es improbable poder realizarlas. En cuanto } \\
\text { a los espacios existentes aunque definidos, no son los más apropiados, son tan reducidos } \\
\text { que incluso el mobiliario en varios casos no cabe, la iluminación y ventilación de los espacios } \\
\text { presenta falencias. }\end{array}$ \\
\hline
\end{tabular}

Fuente: Elaborado por la autora

\section{DESARROLLOS PROGRESIVOS}

Los dos proyectos tienen como objetivo final que la familia pueda mejorar y ampliar su vivienda, la adecúe de acuerdo a sus necesidades y/o presupuesto. En Zapamanga I Etapa, se cumple satisfactoriamente, ya que a la fecha no se conserva ninguna vivienda como fue entregada inicialmente. En el tema urbano también ha mejorado de manera sustancial y aunque el espacio público se ha disminuido, el sector ha logrado incorporarse al municipio con éxito alcanzando estándares de calidad humana. En cambio para la Urbanización Juan Pablo II, aunque es un proyecto relativamente nuevo, lograr tener un progreso requerirá de una inversión y tiempo considerable, lo cual generará sobrecostos con respecto a lo que se tenía planificado en su etapa inicial. 


\section{CONCLUSIONES}

La vivienda, como bien necesario, que todo núcleo familiar debe poseer está supeditada a una serie de factores que alteran su calidad y el desarrollo de las actividades que en ella se realizan. Por tanto, la Vivienda de Interés Social debe ser la consolidación de las familias que la habitan y que se traduce en un mejoramiento físico y social a nivel unitario (vivienda) y general (ciudad).

Se analizaron dos proyectos en dos momentos de la historia con características diferentes, pero que tienen como común denominador el crecimiento acelerado de la población y que la localidad a la que llegan no cuenta con la infraestructura adecuada para recibir a los nuevos residentes. Este indicador muestra el deterioro social en las zonas rurales, debido a la violencia y a las pocas opciones de progreso, estas situaciones son un índice explícito de las migraciones a los centros urbanos, donde las oportunidades para mejorar la calidad de vida de las personas son limitadas.

El aspecto económico es, en definitiva, el más importante en el desarrollo de la Vivienda de Interés Social, ya que prevalece sobre factores como el arquitectónico o urbanístico, de igual manera, establece el resultado final de la vivienda. Los recursos para subsidiar estos proyectos provienen del Estado, encargado de proveer seguridad y vivienda digna a las personas; como es tan alta la demanda de estas soluciones habitacionales, los diseños se deben ajustar a lo que el presupuesto disponga para que haya un mayor cubrimiento, en detrimento de las condiciones óptimas del habitar.

La solución planteada en el Decreto 2060, fue la de bajar las áreas de los lotes y de las viviendas, pero al hacerlo se incrementó el valor del metro cuadrado, lo que encareció la tierra y la vivienda.

La relación entre ubicación y precio del suelo es uno de los generadores de proyectos, ya que las zonas que cuentan con amplios recursos de infraestructura de servicios públicos y equipamiento comunitario y que no necesitan inversiones significativas para el desarrollo de los sectores, no están al alcance de los programas de VIS, pues los valores del suelo son muy elevados.

Las políticas estatales fijan las condiciones del desarrollo de los proyectos y, en este caso, si hay una gran diferencia. Mientras en 1972 el gobierno estaba directamente vinculado a la producción de vivienda, originaba normativas específicas y fortalecía los Institutos y éstos, a su vez, incentivaban la implementación de estándares de diseño que revirtieran en soluciones óptimas, en 2004, la ley fue muy laxa, no hubo un criterio unificado que permitiera hacer diseños y evaluaciones a los proyectos en términos cualitativos y cuantitativos. Si bien es un acierto el trabajo de las Alcaldías y los Planes de Ordenamiento Territorial, siguen los vacíos legales y técnicos que no producen derivaciones concluyentes.

En los dos proyectos se expone el desarrollo progresivo de la vivienda, se parte de que la calidad es un concepto relativo en función de las necesidades de sus usuarios, de ciertas condiciones mínimas de habitabilidad y de las posibilidades de los residentes. En el tema urbanístico es posible que se obtenga un gran desarrollo, puesto que con el tiempo a 
medida que las necesidades son más imperiosas, comienzan a ejecutarse equipamientos e infraestructura que mejoran los sectores. Pero, para el caso de la vivienda como tal, es muy complejo lograrlo, sobre todo en la Urbanización Juan Pablo II, donde el lote es de $35 \mathrm{~m} 2$, y pensar en modificaciones espaciales es casi imposible debido al área mínima.

En la actualidad no hay ningún tipo de entidad a nivel municipal o departamental que regule la calidad de la vivienda de interés social, solamente se tienen datos sobre su déficit. Por otra parte, los centros de educación superior presentes en el área metropolitana tocan este tema sin mayor profundidad.

Es importante que como futuros profesionales desde la academia, aprendamos a valorar la vida en su total dignidad $y$ hacer las gestiones pertinentes para transformar la realidad que es dramática en términos de Vivienda de Interés Social y, por tanto, en el bienestar de las personas.

\section{BIBLIOGRAFÍA}

CARDONA GUTIÉRREZ, Ramiro. Las Migraciones Internas. Bogotá, Editorial Andes, 1976

CEBALLOS RAMOS, Olga Lucía; SALDARRIAGA ROA, Alberto. Vivienda Social en Colombia. Una Mirada desde su Legislación 19 I8-2005. Bogotá, Pontificia Universidad Javeriana, 2008

DEPARTAMENTO NACIONAL DE PLANEACIÓN. Plan de Desarrollo Las Cuatro Estrategias, Gobierno Misael Pastrana Borrero. Bogotá, 1972

INSTITUTO DE CRÉDITO TERRITORIAL, 40 años Construyendo Vivienda para el Pueblo Colombiano. Seccional Santander

Ley 812 de 2003, PLAN DE DESARROLLO 2003-2006. Hacia Un Estado Comunitario. Gobierno Álvaro Uribe Vélez

MOLINA, Humberto. Colombia: Vivienda y Subdesarrollo Urbano. Bogotá, 1979

Revista Escala No 35, INSTITUTO DE CRÉDITO TERRITORIAL, Departamento Administrativo de Planeación Nacional. Estudio de Normas Mínimas de Urbanización, Servicios Públicos y Servicios Comunitarios

ROBLEDO CASTILLO, Jorge Enrique. El Drama de la Vivienda en Colombia, y la Política del "Si se Puede". Bogotá, 1985

TARCHOPULOS SIERRA, Doris; CEBALLOS RAMOS, Olga Lucía. Calidad de la Vivienda dirigida a los sectores de bajos ingresos en Bogotá. Bogotá, 2003 